\title{
Asiáticos en Lima a principios del siglo XVII
}

Les asiatiques à Lima au début du XVII ème siècle

Asians in Lima at the beginnings of the XVII ${ }^{\text {th }}$ century

\section{Mariano Bonialian}

\section{(2) OpenEdition}

\section{Journals}

Edición electrónica

URL: http://journals.openedition.org/bifea/7540

DOI: $10.4000 /$ bifea. 7540

ISSN: 2076-5827

\section{Editor}

Institut Français d'Études Andines

\section{Edición impresa}

Fecha de publicación: 1 agosto 2015

Paginación: 205-236

ISSN: 0303-7495

\section{Referencia electrónica}

Mariano Bonialian, «Asiáticos en Lima a principios del siglo XVII », Bulletin de l'Institut français d'études andines [En línea], 44 (2) | 2015, Publicado el 08 agosto 2015, consultado el 05 noviembre 2020. URL http://journals.openedition.org/bifea/7540 ; DOI : https://doi.org/10.4000/bifea.7540

Les contenus du Bulletin de l'Institut français d'études andines sont mis à disposition selon les termes de la licence Creative Commons Attribution - Pas d'Utilisation Commerciale - Pas de Modification 4.0 International. 


\title{
Asiáticos en Lima a principios del siglo XVII
}

\author{
Mariano Bonialian*
}

\section{Resumen}

El artículo tiene como objetivo conocer las características socioeconómicas de los inmigrantes chinos, japoneses y de la India de Portugal que se encontraban en la ciudad de Lima hacia 1613. El soporte documental utilizado es el Padrón de indios ejecutado por orden del virrey del Perú, el marqués de Montesclaros. El Padrón contempló a todos los indios de la ciudad pero poca mención ha merecido en la historiografía el apartado de los asiáticos allí empadronados. Se brinda un balance historiográfico de la problemática y el contexto de producción que posibilita la realización del censo. La información que se registró en el padrón de los asiáticos residentes en la ciudad es presentada mediante un cuadro, a partir de los siguientes criterios: nombre, edad, ocupación laboral, condición social, tiempo de residencia, lugar de alojamiento y composición familiar. La metodología de recopilación posibilitará un análisis sobre las rutas transpacíficas que permitieron el ingreso de los asiáticos a Lima y los procesos de inserción/segregación vividos por ellos en la ciudad colonial. Finalmente, se emprende un análisis comparativo con los asiáticos que residían en la Nueva España tomando especial consideración la condición social y las ocupaciones laborales.

Palabras clave: asiáticos, Lima, censo, 1613, México, Pacífico

\section{Les asiatiques à Lima au début du XVII ${ }^{\text {me }}$ siècle}

\section{Résumé}

L'article vise à connaître les caractéristiques socioéconomiques des immigrants chinois, japonais et de venant des possessions portugaises en Inde qui se trouvaient à Lima vers 1613. Le support documentaire utilisé est le Recensement des Indiens, effectué sur ordre du vice-roi du Pérou, le marquis de Montesclaros. Le Recensement incluait tous les « indiens » de la ville mais la partie qui correspondait

* Centro de Estudios Avanzados, Universidad Nacional de Córdoba, CONICET, Argentina. E-mail: marianobonialian@gmail.com 
aux asiatiques n'a pas suscité une grande attention de la part de I'historiographie. Ce texte propose un bilan historiographique du sujet et une analyse du contexte de production qui a rendu possible la mise en place du recensement. Les informations sur les asiatiques enregistrés sont présentées dans un tableau organisé selon les critères suivants: nom, âge, métier, condition sociale, temps et lieu de résidence, et composition familiale. La méthode utilisée permet une analyse des routes transpacifiques qui ont permis l'entrée des asiatiques à Lima et de décrire les processus d'insertion/ségrégation vécus dans la ville coloniale. Finalement, I'article fait une comparaison entre les asiatiques de Lima et ceux de la Nouvelle Espagne, en prenant en considération les données sociales et les métiers.

Mots-clés : Asiatiques, Lima, Recensement, 1613, Méxique, Pacifique

\title{
Asians in Lima at the beginnings of the XVII ${ }^{\text {th }}$ century
}

\begin{abstract}
This essay presents the socio-economic characteristics of Portuguese immigrants of Chinese, Japanese and Indian background who lived in Lima around 1613. The supporting documentation used is the Census of Indians produced by the order of the Viceroy of Peru, the Marquis de Montescarlos. The census documents the characteristics of all of the indigenous people living in the city, but gives very little consideration of the historiographical characteristics of Asians who were registered in the census. This article provides historiographical balance on the issue and the context of production of the census. The information recorded in the census of all Asians living in the city is presented in a table based on the following criteria: name, age, occupation, social status, length of residence, place of residence and family composition. This methodology will enable analysis on transpacific routes that would have facilitated the entry of Asians into Lima and the inclusion/social segregation processes that they experienced in the early colonial city. Finally, we offer a brief comparison to the case of New Spain with special consideration of the social status of Asian immigrants based on the occupations they undertook in the City of Kings.
\end{abstract}

Keywords: Asian, Lima, Census, 1613, Mexico, Pacific

\section{INTRODUCCIÓN}

La ciudad de Lima cuenta con uno de los barrios chinos más importantes de Sudamérica. Nuestro sentido común supone que el ingreso de los asiáticos al Perú recién se materializó a mediados del siglo XIX, concretamente en 1849, en el marco de la emancipación y desarrollo de los Estados hispanoamericanos. Esto efectivamente es cierto, pero vale anticipar que existió, si bien en mucho menor grado, una circulación de población asiática hacia el Perú en las tempranas décadas coloniales. Se han realizado grandes avances en el estudio sobre la inmigración en el Perú colonial. Sin embargo, la atención solo se dirigió al espacio trasatlántico, cuantificando el número de europeos y esclavos africanos que descendían de los barcos. La atención de la historiografía hacia la inmigración asiática por el corredor del Pacífico no ha tenido la misma suerte. Y esto resulta curioso porque 
el fenómeno alcanzó un papel significativo no solo en Lima y en el virreinato del Perú, sino también y con mucha mayor fuerza en la Nueva España1.

El presente ensayo tiene como objetivo general reconocer lo que sería el primer grupo significativo de asiáticos que vivieron en la ciudad de Lima colonial, en los años finales del siglo XVI y las primeras dos décadas de la centuria siguiente. La referencia documental será el censo de 1613, titulado Padrón de los indios que se hallaron en la ciudad de los Reyes del Perú, hecho en virtud de comisión del Marqués de Montesclaros, Virrey del Perú por Miguel de Contreras, escribano de Su Majestad2. Lo que nos interesa rescatar del expediente es su último apartado, comprendido entre las fojas 237 y 246, y cuyo encabezamiento es Padrón y lista de los indios e indias de la China y el Japón, e Indias de Portugal que se hallaron en servicio de los españoles en algunas casas de esta ciudad de los Reyes. Curiosamente y a pesar de su notable riqueza informativa, el censo referido a los orientales no mereció un estudio particular por parte de la historiografía. Apoyados en este corpus documental, nuestro objetivo será identificar a estos asiáticos empadronados y caracterizar las condiciones sociales y económicas que llegaron a tener en la temprana Lima colonial.

Consideramos que las referencias en el padrón como «indios e indias de la China, del Japón de las Indias de Portugal» dan cuenta de la aplicación de una categorización sobre los asiáticos, asociada a la imposición de una condición de doble «alteridad». Por un lado, refuerza el carácter extramericano, foráneo, de los asiáticos. Por el otro, los asocia al mundo subalterno de los indígenas andinos. Si bien respetamos la terminología de «indios e indias» en este texto, nos parece más adecuada la utilización de los términos asiáticos $u$ orientales.

El artículo se estructura de la siguiente manera. En un inicio, se realizan breves referencias al contexto de producción del documento y las menciones generales que hizo de él la historiografía. En el segundo apartado, nos aproximamos a la condición socioeconómica de los asiáticos llegados a Lima. Para una mejor fundamentación de nuestras hipótesis, presentamos en un cuadro (anexo 1) la información completa y detallada que aparece sobre cada uno de los asiáticos empadronados. El cuadro se construye bajo los siguientes criterios: nombre, edad, ocupación laboral, condición social, tiempo de residencia en Lima, lugar de alojamiento, composición familiar y, cuando los testimonios lo permiten, a qué encomendero, cacique o «amo» estaban sujetos. Seguidamente, abordamos el problema de las posibles vías o rutas transpacíficas que permitieron el ingreso de los asiáticos a la ciudad. Para finalizar, el artículo presenta un breve análisis comparativo, un paralelismo, sobre el tipo de inserción social y laboral de los residentes asiáticos de la ciudad de Lima y de la ciudad de México.

1 Las referencias bibliográficas sobre orientales en la Nueva España aparecen en citas posteriores.

2 El documento se encuentra ubicado en la Biblioteca Digital Hispánica, en su sección «manuscritos» (Biblioteca Nacional de España, Madrid, mss/3032, II, ff. 256). 


\section{EL PADRÓN DE INDIOS DE 1613: HISTORIOGRAFÍA Y CONTEXTO DE PRODUCCIÓN}

Los investigadores Julián Paz (1933: 724), Ángel Rosenblat (1939) y Rubén Vargas Ugarte (1954: 92-93) fueron los primeros en mencionar la existencia del Padrón de los indios de 16133. Sin embargo, fue recién en 1968 cuando el documento se convirtió en un objeto particular para el análisis histórico. En ese año David Cook le otorgó su justa valoración al realizar su publicación junto con una breve introducción. El esfuerzo de Cook por editar el Padrón de los indios de 1613 merece destacarse no solo por la rica información que contiene el expediente, sino por su carácter inédito puesto que, hasta esa fecha, no mereció una atención particular de los historiadores dedicados al estudio de procesos demográficos, etnológicos y sociales del Perú colonial (Cook, 1968)3. Sin embargo, si bien Cook transcribió y adjuntó al padrón general el apartado referido a los asiáticos, en su análisis introductorio no se detuvo a analizar el caso.

En términos historiográficos, valdría distinguir los trabajos que consideraron, por un lado, el Padrón de indios de 1613 en el marco de un análisis de procesos sociodemográficos y económicos de la Lima colonial y de la América hispana y los que, por otro lado, atendieron el censo de los asiáticos que está integrado al padrón general. En el primer grupo destacan los trabajos de Paul Charney y Miguel Jaramillo. Paul Charney utilizó el padrón para analizar el grado de interacción y asimilación que tuvieron los indios urbanos en la sociedad hispánica dominante (Charney, 1988). Por su parte, en el trabajo de Jaramillo, el padrón se convierte en una caja de herramientas para estudiar la movilidad espacial de los indígenas andinos hacia Lima, logrando insertarse en el aparato productivo de la ciudad y como una fuerza de trabajo con lógicas propias de una economía de mercado (Jaramillo, 1992).

Los trabajos que se acercaron al padrón particular de los orientales son los de Sánchez Albornoz, Lohmann Villena, Iwasaki Cauti y Patricia Palma. Albornoz se refirió de manera general al expediente como una «tercera fuente» de inmigración en la América hispana, que se sumaba así a la europea y africana (Sánchez Albornoz, 1977). Lohmann Villena citó el documento tan solo para demostrar la variedad de colectivos de distintas partes del mundo que se dieron cita en el temprano Perú colonial (Lohmann Villena, 1982: 110-116). El trabajo de Iwasaki Cauti tuvo como principal objetivo estudiar las relaciones comerciales directas que se realizaron entre Perú y Filipinas. Entre otras confirmaciones de su trabajo, logra fundamentar que los asiáticos registrados en el padrón de 1613 no fueron los que inauguraron el movimiento poblacional entre Oriente y Perú, pues desde la segunda mitad del siglo XVI ya se registraba una circulación de un puñado de orientales hacia la ciudad limeña. Considera, por ejemplo, el envío de una nave

3 De aquí en más, la siguiente obra será citada exclusivamente al hacer mención del trabajo introductorio de Cook. 
peruana en socorro de Legaspi (1566) hacia Filipinas que podría haber regresado con asiáticos al Perú (Iwasaki Cauti, 1992: 288-293)4. Finalmente, vale citar el trabajo de Patricia Palma, donde se mencionan a las personas de procedencia japonesa que lograron ser registradas en el censo de 1613 (Palma, 2013). Palma no parece haber tenido el interés de realizar un análisis minucioso sobre las características de la inmigración de todos los asiáticos empadronados en 1613, ni tampoco ofrecer una transcripción integral del expediente. Por lo tanto, partimos de la premisa que el censo de los asiáticos no adquirió en este grupo de trabajos una importancia que lo convierta en un objeto de análisis particular; propósito concreto de este ensayo.

Ahora bien, valdría comenzar con algunos datos mencionados en la introducción de Cook referidos al contexto de producción del censo. El 5 de septiembre de 1613 el escribano del rey, Miguel de Contreras, recibió la comisión del virrey don Juan de Mendoza y Luna, tercer marqués de Montesclaros (1608-1615), de recoger toda la información que fuera posible sobre los indios que habitaban en la ciudad de Lima. La población urbana había crecido de manera muy significativa en los primeros años del siglo y es posible que el virrey necesitara de un actualizado censo poblacional para su gestión. Montesclaros contaba con un «viejo» padrón de la ciudad de Lima que había sido ordenado en 1600 por el virrey Luis de Velasco. Allí se anotó la existencia de 14262 habitantes. Trece años después, el censo que nos ocupa arrojó que la población total era de 25154 personas (Cook, 1968: 2).

Si Montesclaros deseaba ejecutar transformaciones sociales y económicas en el virreinato, resultaba necesario disponer de informes estadísticos que dieran cuenta de los movimientos migratorios y condiciones socioeconómicas de los grupos indígenas. Las transformaciones realizadas durante su mandato en materia fiscal, comercial y social requirieron siempre de revisitas y retasas por varios repartimientos de indios. Si se buscaba optimizar la mano de obra indígena, ya sea para las minas de plata de Potosí, las de azogue situadas en Huancavelica o para controlar a los mitayos, yanaconas y el servicio personal, resultaba necesario obtener información de los corregidores y recorrer cada casa de la ciudad de Lima y del espacio virreinal. Eso es lo que logró el virrey Montesclaros a través del censo de 1613, quizás uno de los más importantes y confiables padrones realizados en el Perú durante la primera mitad del siglo XVII (Jaramillo, 1992: 269).

Montesclaros encontró en el escribano del rey, Miguel de Contreras, el funcionario adecuado para llevar a cabo la gran empresa de empadronamiento sobre los indios de la ciudad de Lima. Contreras recibió la ayuda de los alcaldes, del alguacil mayor y de los mayordomos de cofradías en las visitas de casas y tiendas (Cook, 1976: 37). El 10 de septiembre de 1613 el escribano se disponía a empadronarlos en la parroquia de Santa Ana que pertenecía a los indios, pero no logró iniciar la tarea al celebrarse

4 Por su parte, también se sabe que los embarques de México revelan que dos «indios de la India de Portugal» llegaron al Perú entre 1550-1554. Véase el caso en Borah (1954: 74). 
el día de San Nicolás de Tolentino y pocos indios se encontraban en sus hogares. Los visitadores comenzaron al día siguiente y en noviembre alcanzaron visitar 3163 casas y tiendas de la ciudad de Lima. Sin embargo, según el escribano Contreras fue «muy notorio que el tiempo que se comenzó y fue haciendo el dicho padrón se ausentaron y escondieron muchos para no hacerlo y que pueden haber vuelto a esta dicha ciudad y andan en ella» (citado por Cook, 1968: 5).

Si el detalle y la exhaustividad eran una condición para la elaboración del censo, la tarea no podía quedar incompleta. De tal manera, se ordenó que todos los que no habían sido censados tuvieran que presentarse con los visitadores si no querían sufrir seis días de prisión y dos pesos de multa. Durante el mes de diciembre empadronaron a los indios que faltaban, a los residentes de los conventos de Lima y a «los naturales de Japón, China y de la India». El padrón se completó el 28 de enero de 1614, luego de 4 meses de iniciado el recorrido de visitas (citado por Cook, 1968: 6-7) registrándose, con sumo detalle, aspectos de la vida social y económica de este grupo de inmigrantes procedentes del continente oriental.

\section{CHINOS, JAPONESES E INDIOS DE LA INDIA DE PORTUGAL EN LA CIUDAD DE LIMA}

En 1620, el comerciante portugués León Portocarrero afirmaba que «en Lima y por todo el Perú viven y anda gente de todos los mejores lugares, ciudades y villas de España y agentes de la nación portuguesa, gallegos, asturianos, viscainos, navarreses, aragoneses, valencianos, de Murcia, franceses e italianos, alemanes y flamencos, griegos y raguseses, corsos, genoveses, mallorquines, canarios, ingleses, moriscos, gente de la India y de la China y otras muchas mezclas y misturas» 5 .

La frase nos permite definir la ciudad de Lima de los inicios del siglo XVII como un centro urbano multiétnico. El auge de la producción potosina iniciado en 1580 la convertía en un imán de atracción no solo para los indígenas del espacio peruano, sino también para los comerciantes europeos. Lima vivía por entonces un importante crecimiento económico y la fuerza de trabajo de los esclavos e indígenas de diferente procedencia resultaba fundamental para mantener los niveles de estatus de la sociedad española.

Se ha señalado en páginas anteriores que la ciudad de Lima contaba por esos años con más de 25000 personas. Los esclavos eran el grupo más numeroso (10 386 personas) lo que representaba un 41\% de la población total. Le seguían los españoles con casi el 39\% (9660) y en tercer lugar aparecían los llamados «indios», quienes alcanzaban el $8 \%$ del conjunto poblacional. Dentro de este porcentaje estarían contemplándose los asiáticos. Expresado en el cuadro 1, el padrón de

5 León Portocarrero, «Descripción general del Reino del Perú, en particular de Lima» (1620), Biblioteca Nacional de Francia, Espagnol 280, f. 113. 
1613 arroja que en la ciudad de Lima vivían un total de 2113 indios (Cook, 1976: 35-37). Los «indios de la tierra» o «del Reino» del Perú comprendían el 90,7\% del total, unos 1917 indios. Según Jaramillo, las cifras sobre el número de indios no resultan del todo confiables al delatar cierto sesgo en el censo de Montesclaros. El censo no llegó a contabilizar la población del Cercado, barrio contiguo que albergaba a más de mil indígenas flotantes y quienes tenían muchas razones para evitar ser empadronados (Jaramillo, 1992: 272). A pesar de estas limitaciones, nadie cuestionaría la cercanía de las cifras con la realidad del momento. Cook afirma que el 95\% de ellos no habían nacido en la propia Lima sino que provenían de regiones cercanas, lo cual comprueba la significativa movilidad espacial que se registraba por el virreinato del Perú (Jaramillo, 1992: 265-278). Sin embargo y de manera curiosa, los indios de Chile eran un grupo reducido, tan solo 82 ; lo que resulta un 3,8\% de los indios en Lima.

Los asiáticos superaban en número a los procedentes de Chile. El dato resulta sorprendente porque nos indica la importancia de las relaciones de larga distancia desde una etapa colonial muy temprana. En otros términos, las vinculaciones transcontinentales podían alcanzar una intensidad igual o mayor a las de corta y mediana distancia. El resultado final del censo nos dice que los habitantes de origen asiático en Lima llegaron a ser 114; es decir, el 5,5\% de la población total de indios de la ciudad. Sería arriesgado hablar de una población oriental voluminosa, pero habría que admitir que es un número significativo. De esos 114, 20 eran de procedencia japonesa, 38 de China y 56, prácticamente la mitad, tenían procedencia de la India portuguesa. Ya tendremos oportunidad de explicar la razón de esta mayoría de orientales del Estado da India.

Como ocasionalmente sucede en los padrones, valdría advertir que en el caso de los asiáticos existen ligeras diferencias entre el conteo particular que arrojó la visita casa por casa con el balance final. El cuadro del anexo 1 que aparece, construido sobre las visitas realizadas por el escribano Contreras y sus ayudantes por cada hogar o tienda de la ciudad resulta ser nuestro principal cuerpo de información a analizar. Se desprende de él que en Lima, considerando a los hijos y esposos/as de los empadronados, vivían 109 habitantes del Oriente. Sin embargo, el escribano subrayó en los resultados finales la existencia de 114 individuos procedentes de Asia. Esta ligera diferencia se explicaría por los «indios ausentes» omitidos en las visitas reales, pero que fueron considerados en la suma total.

De aquí en adelante tomaremos como referencia dicho cuadro. Allí se contabilizan 73 registros personales de orientales, los 36 que faltarían para llegar a aquella cifra de 109 serían esposos/as e hijos/as que fueron registrados en los anexos del sujeto particular que fue empadronado ${ }^{6}$. Podemos conocer la procedencia específica de algunos asiáticos. Están los denominados con el término «China, de Manila».

6 La cifra que figura en el padrón no estaría expresando el número exacto de los asiáticos que por esos años estarían residiendo en Lima. Sabemos de la existencia de un maestro chino llamado Juan Pablo responsable de la construcción de El Puente de Piedra de Lima en el año 1608, y de asiáticos instalados en el puerto de El Callao para el trabajo de carpintería de barcos. Agradezco a uno de los evaluadores anónimos esta última observación. 


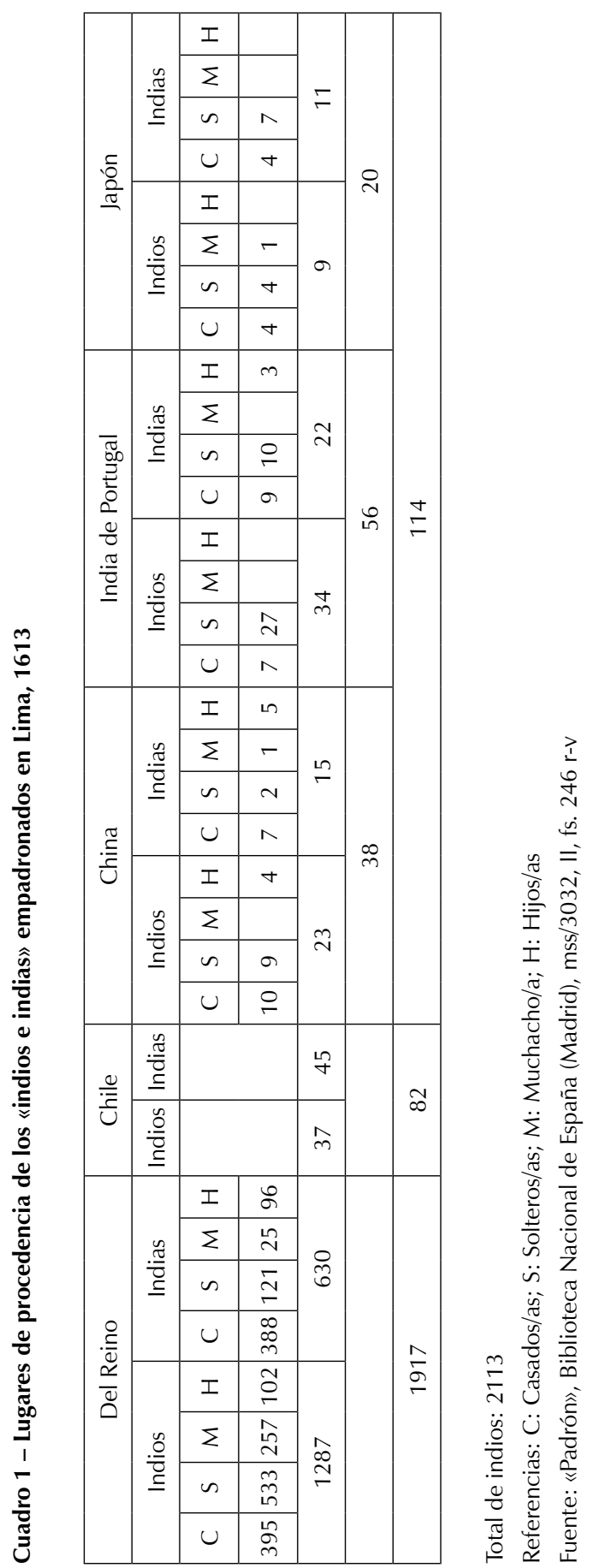


La noción desprende dos explicaciones alternativas: podría hacer referencia a personas de Filipinas que fueron evangelizadas en las islas, o bien a poblaciones de diferentes puntos de China que fueron movilizadas al archipiélago filipino, bastión español para la conversión religiosa emprendida por los jesuitas y otras órdenes religiosas (Colín, 1904 [1663]). Asimismo, surge una segunda duda que si la noción «China, de Manila» daba cuenta del lugar exacto de nacimiento del empadronado o su punto de partida en el derrotero que emprendían hacia México o Lima. Macon, Pampanga y Bonbon fueron otros de los lugares mencionados de los inmigrantes chinos. Una gran porción de los de «la India de Portugal» eran de Malaca, pero también Ilegaron desde Goa, Piso, Macao, Camboya, Cuebi [sic] — ¿Cebú?_-, Busarate y Salao [sic] —iPalao?_. Solo un japonés dijo su lugar de procedencia: Mangacate [sic]. Como se fundamentará más adelante, todos los asiáticos Ilegaron a Lima por el Pacífico, en dos posibles derroteros: el que partía de Filipinas haciendo escala en México o, como lo demostró el historiador Iwasaki Cauti, por la vía directa entre el archipiélago oriental y el puerto de El Callao en las últimas dos décadas del siglo XVI (Iwasaki Cauti, 1992).

$\mathrm{Al}$ analizar los matrimonios de los orientales, vemos que 68 de los 73 asiáticos empadronados respondieron sobre su condición nupcial. Unos 26 estaban casados y 42 eran solteros. De los 26 orientales casados 15 eran chinos, 9 provenían de la India de Portugal y 1 era japonés. Por su parte, los solteros se dividían en 10 chinos, 27 de la India de Portugal y 5 japoneses. Resulta interesante notar que el matrimonio primaba entre los chinos mientras que la soltería era un denominador común entre los de la India de Portugal. Si bien los datos nos impiden sacar conclusiones, es posible pensar que muchas de las uniones entre los propios chinos fueran previas a su llegada a Lima o gestadas en el transcurso del derrotero que pasaba por Filipinas y México. Esta diferencia con los de la India de Portugal podría explicarse, en primer lugar, porque la mayoría de los chinos se habrían evangelizado en las Filipinas (Colín, 1904 [1663]); un proceso de conversión que no habrían vivido los asiáticos de la India de Portugal. Otra razón, pero relacionada con la anterior, habría sido las diferencias en los modos de inserción social y laboral, puesto que los chinos, como veremos más adelante, registraron una mejor condición económica por contar con un oficio o actividad artesanal en la ciudad. Por su parte, los de la India de Portugal eran, en su gran mayoría, esclavos. De las veintiséis parejas, solo en diez casos se dijo tener hijos. La procreación también es un reflejo de la mejor condición de vida de los chinos en comparación con los inmigrantes de la India portuguesa: en ocho casos los hijos eran de padres chinos, mientras que en solo dos ocasiones los hijos venían de madre o padre originario de la India de Portugal.

Pero lo que más atención reclama es la notable diversidad de orígenes en las uniones; lo que nos confirma de un temprano proceso de mestizaje. Tenemos a mujeres de la India de Portugal casadas con chinos (caso 9 y 45 del anexo 1); un chino con una de la India de Portugal (4 y 11); una china con un indio «criollo y zapatero» (7); Juana de Sigura, otra china, con un «indio mestizo y minero» (14); una mujer de la India con un mulato (28); Susana, otra de la India portuguesa con 
un sastre del «reino de Granada» (34); un chino con Catalina Guatalca que es «de acá», del reino del Perú (12), otro chino con una «india mestiza de Huánuco (23) y otro chino con una india de México, de Tlaxcala (39); un asiático de la India de Portugal con una «esclava morena» (30 y 58); un chino con una «negra libre» (41); un hombre de la India portuguesa con una india japona (46); un chino con una «negra criolla» o «negra libre» (33 y 26) y, finalmente, un japonés con una india de la India de Portugal (31)7. En fin, resulta difícil saber los motivos de este temprano proceso de mestizaje entre asiáticos de distinta procedencia, así como también entre asiáticos e indios locales y esclavos africanos. Aún con condiciones laborales adversas de las que nos ocuparemos en las páginas siguientes, no se podría asimilar la situación de los asiáticos con los africanos. Pero los datos del padrón nos están indicando una relativa integración del grupo de los asiáticos al conjunto de la sociedad. Su vida laboral en tiendas artesanales o aún como esclavos y los prolongados períodos de residencia en Lima habrían permitido que los asiáticos se contacten con otros grupos étnicos. Estos grupos étnicos tenían una vida de hogar compartida. Como lo indica la columna «residencia» del anexo 1, las casas de residencia de los asiáticos pertenecían a mercaderes — españoles y extranjeros - o funcionarios de la ciudad. Si atendemos a la ubicación de las casas se concluye que estamos en presencia de un espacio geográfico relativamente reducido; donde en un radio espacial que no pasaría de las seis o siete cuadras interactuaban los diferentes grupos étnicos bajo una vida cotidiana compartida (Charney, 1988) ${ }^{8}$.

Resulta interesante mencionar algunos de los propietarios de los inmuebles donde vivían los asiáticos; personalidades que figuran en la columna «residencia» del anexo 1. Allí se pueden identificar personalidades políticas importantes como comerciantes españoles y de procedencia judeo-conversos (marranos). Aparece Diego Núñez de Campoverde, cuya residencia se situaba en la calle de Los Estudios y en su servicio contaba con cuatro asiáticas: tres de China y una oriunda de Malaca. Campoverde se destacó por emprender actividades comerciales con España y México; una profesión que lo llevó a posicionarse entre los miembros más conspicuos del Tribunal del Consulado de Lima (Lohmann Villena, 1983: 250252). Como se sabe, los comerciantes portugueses de origen judío constituyeron un sector mercantil clave del comercio peruano de la época. Se caracterizaron no solo en el tráfico negrero abasteciendo los diferentes centros económicos del Perú por la vía de Buenos Aires y desde las costas de Portobelo sino también, como de manera brillante lo demostró Wachtel con el caso de Manuel Pérez,

7 En suma, estamos lejos de presenciar un patrón exclusivo de matrimonio endogámico, de preservación étnica entre los asiáticos. No se ha trabajado con adicionales datos parroquiales de información de bautismo o uniones que podrían encontrarse en los archivos de Lima, lo que nos hubiera permitido reflexionar en torno a este problema.

8 No habría relación o cierta continuidad espacial entre el asentamiento asiático colonial que aparece en el Padrón con el actual Barrio Chino que hoy tiene Lima, pues este se ha constituido después de la construcción del Mercado de La Concepción en un barrio donde habían huertas y jardines para el abastecimiento de Lima, conventos, casas aristocráticas y de la nueva burguesía republicana. Agradezco al evaluador anónimo esta observación. 
en la importación de ropa de China desde México (Wachtel, 2001: 324-256). Más de veinte portugueses habían obtenido el permiso de hacer el comercio en el Perú, siendo el mayor número de los extranjeros con permiso a finales del siglo XVI (Rodríguez Vicente, 1968: 619-621). Llegaron a tener tanto poder los comerciantes marranos que incluso «la calle que llaman de los mercaderes era casi toda suya» (Medina, 1956, tomo 2: 46). Algunos de los asiáticos que figuran en el padrón de 1613 vivían en las casas de estos ricos mercaderes de origen portugués, tales como Gaspar Méndez o Lucas Jerez, entre otros.

Por otro lado, las edades de los asiáticos registrados en el padrón iban desde los 12 hasta los 40 años. Naturalmente todos tenían «edad activa», productiva. Exceptuando la categoría de «hijos», contamos con la edad de 61 asiáticos. La escala de edades era la siguiente: se empadronaron 9 asiáticos que iban desde los 10 hasta los 19 años; entre los 20 y los 29 años eran 37 y entre los 31 a los 40 años el número llegaba a 15. Más de la mitad de los empadronados se encontraba en la franja de los 20-30 años. Sin embargo, era considerable el número de chinos y de la India de Portugal que tenían una edad mayor para la época, unos 40 años (8 casos). Seguramente, muchos de ellos estaban en Lima desde hace mucho tiempo.

De los 109 asiáticos que, según el padrón, residían en Lima, casi la mitad (49) dio cuenta del momento explícito de su arribo. La mayoría que reconoció el momento de su ingreso a Lima eran los «chinos de Manila», unos 26; 18 fueron de la India de Portugal y solo 5 japoneses recordaban el año o el momento de su llegada. Como puede observarse en el cuadro 2, la inmigración asiática se concentró en la primera década del siglo XVII. De un total de 49 asiáticos que respondieron a la pregunta, en 33 casos el arribo se produjo en los años comprendidos entre 1600 y $1610^{9}$. Curiosamente, era la coyuntura en donde las leyes prohibitivas para el movimiento de bienes, plata y personas entre Perú y el Oriente alcanzaron su cota máxima, pero también el momento en donde, según el fino análisis de Ramiro Flores, el comercio asiático desde la Nueva España hacia el Perú vivió su momento de esplendor (Flores, 2005: 402-406). En este sentido, para comprender la inmigración asiática debemos necesariamente integrar al análisis dos fenómenos plenamente articulados. Por un lado, las posibles rutas de ingreso que les permitieron a los orientales llegar a Lima y, en segundo lugar, la reacción de quién fue el promotor del censo, el virrey marqués de Montesclaros, frente a la política comercial prohibitiva que ordenó la corona española para el tráfico entre China, México y Perú.

9 Desconocemos la razón por la cual el historiador Iwasaki Cauti sostiene que solo «seis personas habían llegado al Perú entre 1580 y 1590; tres entre 1590 y 1600 y ocho entre 1600 y 1610 ». La información que aquí se presenta no coincide en varios puntos a la ofrecida en su obra. Véase Iwasaki Cauti (1992: 293-294). 
Cuadro 2 - Año de ingreso a la ciudad de Lima

\begin{tabular}{|l|c|c|c|c|c|c|}
\hline \multirow{2}{*}{} & \multicolumn{2}{|c|}{$1590-1599$} & \multicolumn{2}{c|}{$1600-1609$} & \multirow{2}{*}{ Total } \\
\cline { 2 - 7 } & $1590-1595$ & $1596-1599$ & $1600-1605$ & $1606-1609$ & & 2 \\
\hline China & 5 & 1 & 13 & 5 & 2 & 26 \\
\hline India de Portugal & 3 & 1 & 7 & 5 & 2 & 18 \\
\hline Japón & 8 & 2 & 20 & 13 & 6 & 5 \\
\hline & \multicolumn{2}{|c|}{10} & & 33 & 6 & 49 \\
\hline Total & \multicolumn{2}{|c|}{10} & & 3 & 2 & 4 \\
\hline
\end{tabular}

Fuente: Elaboración propia en base al padrón (anexo 1)

\section{LA RUTA DE INGRESO DE LOS ASIÁTICOS A LIMA}

Nos resulta curioso que el principal interesado en reunir información sobre los asiáticos en Lima haya sido el virrey Montesclaros; uno de los más enérgicos defensores en abrir la ruta de comercio de bienes orientales desde Filipinas hacia México y Perú. En 1579, unos años después de formalizarse las relaciones comerciales del galeón de Manila uniendo el archipiélago oriental con el puerto novohispano de Acapulco, la corona española autorizó el tráfico directo de productos asiáticos y plata entre China, Filipinas y toda la franja occidental hispanoamericana (México, Centroamérica y Perú). Sin embargo, al notar los perjuicios que ocasionaba el comercio transpacífico sobre el flujo trasatlántico, Felipe II decidió en 1604 reducir la contratación de China exclusivamente a México, con un comercio rígidamente regulado por el galeón de Manila. De tal manera, el espacio peruano quedaba oficialmente marginado de cualquier trato, ya sea directo o con previa escala en Acapulco, con el Extremo Oriente (Borah, 1954: 20-45; Schurz, 1992 [1939]: 236-245).

Montesclaros, principal interesado en la realización del Padrón de 1613, estuvo muy atento al proceso legislativo de cierre comercial por el Pacífico. No solo llegó a tener un pleno conocimiento del comercio triangular entre Filipinas, México y Perú sino que además lo promocionó a pesar de las restricciones implementadas por la política metropolitana. Montesclaros no estaba de acuerdo con la prohibición que regía desde principios del siglo y que apartaba al Perú del comercio asiático. Decía que, a pesar de las leyes que lo impedían, el tráfico de ropa china desde Acapulco hacia los puertos del Perú continuaba creciendo porque giraba en torno a los intereses de los grandes comerciantes de Lima y de la ciudad de México; muchos de ellos integrantes de sus respectivos consulados. Estos ricos mercaderes no veían ningún impedimento en promocionar la ruta comercial ya que gozaban de la complicidad de las autoridades portuarias. Ante ese escenario, Montesclaros llegó a proponer su legalización para que la corona española tenga la posibilidad 
de obtener caudales en calidad de impuestos ${ }^{10}$. De hecho, en su mandato como virrey de México (1603-1617) protegió los intereses y las inversiones de capitales que hacían, en contra de la legislación, los comerciantes de la ciudad de México. En los años siguientes (1607-1615), cuando asumió como máxima autoridad del virreinato andino, Montesclaros encubrió muchos casos de contrabando realizados por naves peruanas que venían desde México colmadas de ropa asiática11. En 1610, el presidente de la Audiencia de Panamá, Francisco de Valverde, resumía de manera muy acertada el gran fenómeno del contrabando asiático realizado desde México hacia el Perú. Decía:

La ciudad de Lima como las demás partes están llenas de mercaderías de China en tiendas públicas con harta publicidad y unas naos fueron dejando por todos los valles de donde se distribuye al distrito y ciudad de Quito, a la gobernación de Popayán, Yagualsongo, Piura, Saña y Trujillo12.

En suma, el comercio asiático desde México hacia El Callao superó con éxito cualquier escollo impuesto por la ley, viéndose acompañado por un movimiento de personas de las que, una gran porción, eran asiáticas. En condición de esclavos o libres, ellos llegaron a México en el galeón de Manila y prosiguieron su viaje hacia el Perú, junto con el contrabando de productos orientales destinados al abastecimiento de los mercados consumidores del espacio andino. En tiempos del virrey Montesclaros el movimiento de asiáticos desde México hacia el Perú fue muy significativo, expresándose, solo en parte, en el Padrón de 1613. Si prestamos atención al anexo 1 veremos que ante la pregunta sobre el tiempo de residencia o lugar de procedencia, algunos chinos, japoneses y de la India de Portugal respondieron haber llegado al Perú «desde México» (casos 10, 17, 27, 34, 39 y 43 ), o con la frase «con el virrey Velasco» (44), «con Monterrey» (4) o con el propio Montesclaros (31). Estas afirmaciones que se explicitan en el censo confirman que algunos orientales habrían ingresado a Lima con quien ordenó la ejecución del empadronamiento y que los virreyes del Perú previos a Montesclaros venían de México por el mar del Sur acompañados en el cortejo por asiáticos de toda condición social. Por otra, se podría sugerir que algún «indio del Japón» anotado en el censo haya llegado previamente a México en el San Buenaventura que salió en 1610 desde el Japón al mando de Rodrigo de Vivero y tocó en ese mismo año el puerto de Matanchel, en Nayarit (Sola, 1973: 277)13.

10 Para un análisis detallado, véase Latasa \& Fariñas (1991: 25-26).

11 Su sobrino, Rodrigo de Mendoza, y su secretario, Gaspar Rodríguez de Castro, fueron formalmente acusados de contrabando por ingresar géneros asiáticos al Perú desde Acapulco (Latasa Vasallo, 2002: 892-893).

12 «Carta del presidente de Panamá Francisco Valverde», 1610, Archivo General de Indias, Sevilla (AGI), ramo Panamá, Volumen 16, registro 2, núm. 23, f. 11.

13 En 1614, llegaron desde Sendai 150 japoneses a Acapulco en una comitiva formal para la inauguración de una embajada japonesa en México. Claro está que este grupo de nipones no figuran en el padrón por ser un fenómeno posterior (León-Portilla, 1981: 225-228). Para un estudio sobre la inserción de estos japoneses al virreinato de la Nueva España, véase Calvo (1983) y Reyes \& Palacios (2011: 191). 
Pero ifue la nao de China la única vía de entrada de los asiáticos hacia Lima? Algunos orientales que figuran en el padrón habrían arribado a la ciudad de Lima por la ruta directa entre Filipinas y el puerto de El Callao. Como lo ha demostrado Iwasaki Cauti la vía de comunicación directa entre esos puntos, evitando la escala en algún puerto novohispano, funcionó durante las últimas dos décadas del siglo XVI. En 1580 el navío Nuestra Señora de la Cinta, con Gonzalo Ronquillo, quien fuera gobernador de Filipinas, inició la travesía de ida y vuelta. En 1583, la nave volvió a realizar la ruta, en esta oportunidad bajo el mando de Juan de Mendoza. En 1589 lo hizo con otra nave Juan de Solís y al año siguiente fue García de Mendoza, marqués de Cañete y octavo virrey del Perú, quien emprendió el derrotero (Iwasaki Cauti, 1992: 48, 72 y 228). Al ser una ruta prohibida, es posible que se hayan realizado otros viajes sin contar con rastros documentales. Lo cierto es que hacia finales del siglo XVI, el derrotero fue una vía frecuente para el movimiento de cargamentos de ropa asiática, plata potosina y un ejército de tripulantes con una trama social de lo más diversificada (mercaderes, religiosos, esclavos, marineros, etc.). Según Iwasaki Cauti, muchos de los jesuitas que llegaron al Perú en esos barcos estaban acompañados de esclavos asiáticos de la India de Portugal. El autor relaciona esta información con el caso n. 61 del anexo 1, en donde se menciona a una india de la India de Portugal Ilamada Felipa que está casada con Antón, un esclavo de los teatinos (jesuitas) (Iwasaki Cauti, 1992: 294). En suma, es factible suponer que un puñado de orientales registrados en el padrón, en particular los de mayor edad, hayan ingresado a Lima por esta vía directa. La ruta entre Filipinas y Perú se cortó hacia finales del siglo XVII con la legislación peninsular que prohibía el trato del Perú con China. Sin embargo, a raíz de que los mecanismos de ocultamiento eran más fáciles, la escala por Acapulco continuó funcionando al menos hasta las primeras tres décadas del siglo ${ }^{14}$.

\section{CONDICIÓN SOCIAL Y OFICIOS DE TRABAJO: UNA COMPARACIÓN CON LA NUEVA ESPAÑA}

Veamos, por último, la condición social y la ocupación laboral de los asiáticos residentes en la ciudad de Lima emprendiendo un paralelismo con los inmigrantes asiáticos instalados por esos mismos años en el virreinato de la Nueva España. Según el anexo 1, 69 asiáticos de los 109 computados en el padrón de 1613 reconocieron su condición social, ocupación laboral u oficio. Prácticamente, la mitad de ellos eran esclavos (36); en la que primaban los de procedencia de la India de Portugal (30). Es posible suponer que algunos de los clasificados en el padrón como «siervos de la casa» (8) fueran esclavos donde también eran mayoría los venidos de la India (5).

14 Una abundante bibliografía confirma el hecho. Basta citar aquí los trabajos de Navarro García (1965) y Suárez (1995). 
Para comprender la presencia de esclavos de la India en Lima habría que dirigir la mirada a la ruta del galeón de Manila. El trabajo de Débora Oropeza nos informa que entre 1565-1673 arribaron aproximadamente 3872 esclavos asiáticos al puerto de Acapulco (Oropeza, 2007: 467-450; 2011: 32-33). Desde un inicio Oropeza advierte que estaríamos en presencia de una cifra mínima, poco representativa, puesto que no contempla la entrada sin registro de los esclavos por Acapulco y de otros puertos menores del espacio. Más cercana a la realidad parece ser la cifra brindada por Jonathan Israel quien sostiene la llegada de 6000 esclavos asiáticos en cada década comprendida desde principios hasta mediados del siglo XVII (Israel, 1975: 45). Sin intenciones de establecer un número preciso, lo cierto es que la mayoría de ellos llegó a Acapulco procedente del Estado da India. Uno de los motivos más importantes habrían sido las leyes flexibles y permisibles que regían para su tráfico en Goa (Seijas, 2008)15. La necesidad de mano de obra barata para el trabajo de las minas americanas también resultó un factor de arrastre de la inmigración de esclavos de la India de Portugal. En 1572 Felipe II mandó una real cédula al gobernador y oficiales reales del archipiélago oriental para que se evalúe la posibilidad de enviar esclavos asiáticos para el trabajo en las minas de la Nueva España y del Perú (Seijas, 2008: 37). La brutal caída demográfica de la población indígena obligaba a buscar nuevas fuentes de mano de obra en la actividad minera. Claro está que la dimensión del ingreso de esclavos orientales a la América colonial no podría compararse con los flujos trasatlánticos de esclavos africanos ${ }^{16}$. No obstante, como lo demuestra Slack, la presencia de esclavos y sirvientes asiáticos en los espacios hispanoamericanos fue relativamente importante (Slack, 2010: 11-12).

La arribada de asiáticos de la India portuguesa hacia México se vio estimulada por los traficantes al no cargar con ningún tipo de impuesto aduanero. Recién en 1612, un año antes de la confección del padrón de indios de 1613, se gravaron tarifas sobre este rentable comercio. Una notable cantidad de traficantes portugueses se instalaron en las islas Filipinas para negociar la venta de esclavos de la India. La presencia portuguesa en Filipinas declinó recién en 1644, cuando la Corona española decretó la prohibición definitiva de la presencia portuguesa en las islas (Seijas, 2008: 20; Oropeza, 2011: 28). El comercio negrero era un rentable negocio para los comerciantes, puesto que un esclavo de la India de Portugal podía adquirirse en 100 pesos en Manila y venderse en Acapulco a 420 pesos (Oropeza, 2011: 17). Por todo lo dicho podríamos sostener que muchos de los asiáticos que aparecen en el padrón de 1613 fueron reexpedidos a la ciudad de Lima por la vía novohispana. El anexo 1 muestra que de los nueve casos de «indios» que se identificaron con procedencia mexicana más de la mitad de ellos, cinco, eran originarios de la India de Portugal.

15 Véase también Scott (1991: 138-167). Ocasionalmente, algunos de los esclavos asiáticos importados a México se reexpedían hacia España por el Atlántico (Slack, 2010: 13).

16 Según Vega Franco, 72100 esclavos africanos entraron al puerto de Veracruz en los años 1595-1640 y 1663-1674, de tal manera que el ingreso de esclavos a Acapulco representó en comparación, con base en las cuentas de la Caja de Acapulco, cerca de 5\% (Oropeza, 2011: 35). 
A raíz de la escasa información que nos ofrece el padrón, pocas reflexiones se pueden brindar sobre el caso de asiáticos «libres». Es posible suponer que los libertos fueron más de aquellos cuatro casos que figuran en el expediente. No obstante, en algunos asiáticos donde el visitador omitió su condición social se logra explicitar, como podemos ver en el anexo 1, que su esposa/so era libre, lo que habría sido posible que el matrimonio fuera libre (.$^{\circ} 33$ y 41). Asimismo, los chinos que contaban con tienda propia para realizar su oficio podrían haber sido libres pero tampoco disponemos de una mención explícita de tal condición. Llama la atención el caso 31 del anexo 1, donde aparece un japonés anónimo venido de «Mangacate» [sic], donde «todos son libres». Era abridor de cuellos y soletero y liberó a su esposa esclava de la India de Portugal por 300 pesos. O el caso 26 del anexo 1 que da cuenta de un chino venido de «Pampanga» que no tuvo «cacique ni amo» y ejerció asimismo el oficio de soletero. Tampoco tenemos posibilidad de rastrear el tipo de relación laboral que se estableció entre los asiáticos con sus amos o empleadores. Contamos con solo un caso donde una mujer de la India de Portugal, María Vázquez, cobró «un salario» por el servicio doméstico que realizaba en una casa de españoles (35).

Según el cuadro 3, existieron un total de 20 asiáticos dedicados al oficio de soletero y abridor de cuellos; 14 de ellos, el 75\%, eran chinos. El trabajo de soletero consistía en modelar telas o lienzos con la planta de los pies que van debajo de las medias, una suerte de «plantillas». Por su parte, el abridor de cuellos se ocupaba de moldear los cuellos de lienzo sobrepuesto al cabezón de la camisa. Lo cierto es que ambos oficios requerían un especial manejo de las telas y sedas; actividad que resultó muy familiar en los orientales por la fama de las sedas y vestidos producidos en su espacio originario.

Aquella cifra de veinte asiáticos dedicados al oficio no coincide con las brindadas por Cook y Jaramillo en sus análisis sobre la estructura ocupacional de todos los indios de Lima. Según ellos, el padrón de 1613 arroja un total de once abridores de cuellos indios en toda la ciudad (ocho indios y tres muchachos) (Cook, 1968: 12; Jaramillo, 1992: 291). Es evidente aquí un error estadístico. Tan solo el grupo de los asiáticos que se registran en el padrón dedicados al oficio eran veinte; cifra que duplicaría el número brindado por Cook y Jaramillo de los supuestos once abridores de cuellos en toda Lima. De la misma manera, los chinos dedicados al oficio de soletero y abridores de cuellos constituyeron el grupo de los asiáticos que alcanzaron la más elevada posición económica, pues vemos que en varios casos disponían de tiendas propias. Sobresalen en el anexo 1 el caso de dos chinos: el de Andrés Pérez de 32 años (caso 25) y Andrés Jerez (39). Ambos contaban con negocio propio para realizar su oficio en la principal calle de negocios de Lima, la llamada «calle de los mercaderes»17. Al margen de las diferencias en las estadísticas,

17 Vale aquí la definición que nos ofrece León Portocarrero: «La calle de los mercaderes siempre hay por lo menos cuarenta tiendas llenas de mercaderías surtidas de cuantas mercaderías tiene el mundo [...] aquí está todo el principal negocio de Lima y pocos ricos tienen tienda», en Portocarrero, «Descripción» (1620), Biblioteca Nacional de Francia, Espagnol 280, ff. 80-81. 
Asiáticos en Lima a principios del siglo XVII

Cuadro 3 - Condición social, ocupaciones y oficios de los asiáticos en la ciudad de Lima en 1613

\begin{tabular}{|l|c|c|c|c|}
\hline \multicolumn{1}{|c|}{ Condición/ocupación } & de China & $\begin{array}{c}\text { de la India de } \\
\text { Portugal }\end{array}$ & de Japón & Total \\
\hline Esclavos & 6 & 30 & 36 \\
\hline $\begin{array}{l}\text { Soletero y/o abridor de } \\
\text { cuellos }\end{array}$ & 14 & 3 & 3 & 20 \\
\hline Servicio doméstico & 3 & 5 & & 1 \\
\hline Sastre & 1 & 1 & & 1 \\
\hline Cantero & 1 & 1 & & 1 \\
\hline Albañil & & & & 1 \\
\hline Bordador & & 1 & & 1 \\
\hline Cocinero & 1 & & & 1 \\
\hline
\end{tabular}

Fuente: Elaboración propia en base al padrón (anexo 1)

lo que parece cierto es que los asiáticos eran el grupo que monopolizaba esta práctica de oficio, aunque no necesariamente llegaron a conformar un gremio reconocido y respetado.

La dedicación de los chinos a un oficio particular también ocurrió en México, pero en otro tipo de actividad. Por estas mismas décadas, en la plaza mayor del Zócalo del centro de la ciudad de México, los chinos practicaron el oficio de barberos. Resultaba ser una actividad a la que actualmente se dedican los llamados peluqueros (corte de cabello y barba) y de tratamientos vinculados a la salud (limpieza de oídos y cirugía dental) (Slack, 2010: 14-17). En la plaza mayor de la ciudad de México, los asiáticos lograron tener sus propias barberías. De hecho, llegaron a ser tantos los chinos dedicados a este tipo de actividad que no solo compitieron con el monopolio que hasta entonces detentaban los barberos españoles sino que demandó, durante varias décadas, la aplicación de leyes para limitar la expansión de barberías chinas por la calle principal del Zócalo de la ciudad. Con el fin de regular la expansión de las barberías de chinos, pues muchos de ellos pudieron contar con tienda propia, las leyes peninsulares limitaron a doce barberías de chinos en la ciudad y llegaron a prohibir el contrato de aprendices orientales en ellas'18.

Estas particulares inclinaciones laborales de los asiáticos en la ciudad de Lima y de México - en la primera como abridores de cuello/soleteros y en la segunda

18 Archivo General de la Nación (México), Reales Cédulas, 27, f. 40; Indiferente virreinal, caja 1587, 16, ff. 1-4. 
como barberos - suponen una difícil inserción a la sociedad colonial en general. En México hubo una elevada resistencia por incorporar a los asiáticos en el mundo del trabajo. Hasta se creó una «comisión de barberías anti-chinas» para impedir su dedicación en el oficio (Slack, 2010: 15). En Lima, como ya hemos anticipado, el oficio de soleteros y abridores de cuellos también habría generado cierta resistencia en la comunidad española, impidiendo la constitución de un gremio en ese particular oficio. Si bien no tenemos información precisa de lo ocurrido en torno a esos chinos soleteros y abridores de cuellos, sabemos que en las reglas corporativas de algunos gremios de la ciudad de Lima se prohibía el ingreso a todo individuo que no sea español, como mulatos, negros y propiamente chinos ${ }^{19}$. Seguramente estas reglas de exclusión y segregación social también se activaban en términos de condición socioeconómica. En definitiva, los asiáticos se habrían visto obligados a crear mecanismos de resistencia para luchar con una sociedad hispana donde la marginación, la exclusión y la segregación social eran una norma corriente.

En el cuadro 3 aparecen varios asiáticos cuyo trabajo fue definido por el visitador como «siervos de la casa». Es posible que muchos de ellos fueran esclavos. Al igual de lo que sucedió en el virreinato de la Nueva España, en donde los esclavos orientales fueron transportados desde Acapulco hasta la ciudad de México (Oropeza, 2011: 39), los que ingresaron al Perú fueron conducidos a la ciudad de Lima para su empleo en el servicio doméstico en las casas de autoridades políticas o ricos mercaderes españoles o portugueses. Finalmente, como oficios restantes, se registran un chino sastre, otro cantero y un albañil. De la India de Portugal se empadronaron un bordador y un cocinero.

\section{CONCLUSIONES}

En el presente ensayo nos tomamos la tarea de presentar el grupo de orientales procedente de China, de la India de Portugal y Japón instalados en la ciudad de Lima a partir del Padrón de 1613. Seguramente estamos lejos de haber contemplado todos los asiáticos que vivían en la Lima colonial de principios del siglo XVII al atender exclusivamente este preciso corpus documental. Si hubiéramos tenido como objetivo esta segunda intención estaríamos obligados a consultar diferentes archivos que se ubican en Lima y en todo el Perú. Sin embargo, como se expresa en el título de este ensayo, la intención fue realizar un primer acercamiento a una fuente que, como objeto de estudio particular, no había sido trabajada hasta el momento.

${ }^{19} \mathrm{Si}$ bien no se conocen reglas de exclusión sobre la población indígena para integrar gremios, ocurrieron de hecho prácticas discriminatorias en la regulación gremial. Por ejemplo, en el gremio de los botoneros, no se aceptaban «sambos, chinos, ni mulatos». En el de los sastres, jubeteros y tintoreros se prohibía el ingreso de negros, mulatos y esclavos a tener tienda propia, pero sí en relación de dependencia. Para mayor detalle véase Jaramillo (1992: 286). 
De acuerdo con el Padrón se comprobó que el grupo de asiáticos representó el $5,6 \%$ del total de indios que trabajaban en la ciudad; una cifra importante, no menor, que expresa la elevada actividad que, desde épocas tempranas, tenían los vínculos intercontinentales. Al reconocer el Pacífico como un espacio de movilidad espacial, como una fuente de inmigración tan importante como la del espacio Atlántico, podemos comprender con mayor hondura por qué razón las principales urbes coloniales como México y Lima llegaron a ser ciudades multiétnicas; puntos de confluencia de personas procedentes de diferentes partes del mundo, venidas desde Europa o del Oriente.

El Padrón de indios de 1613 representa un fiel reflejo de estos procesos de interacción y movilidad social que traspasaron la frontera geográfica del imperio español. El área mercantil del Pacífico se integró al proceso de mundialización de la época, erigiéndose como una pieza clave en la movilización de los asiáticos desde el Oriente hacia México y Lima. Intentamos demostrar que los asiáticos ingresaron a Lima a través de dos derroteros. La ruta más utilizada fue la que unía a Filipinas, Acapulco y Perú, impulsada en el primer trayecto por el galeón de Manila y en su segundo tramo por embarcaciones peruanas que regresaban desde Acapulco hasta el puerto de El Callao con bienes asiáticos, europeos, de la tierra y personas. Otra vía de inmigración habría sido la que conectaba directamente a China con Perú cuyo funcionamiento, como lo ha demostrado Iwasaki Cauti, puede registrarse desde las últimas décadas del siglo XVI.

El ingreso de los asiáticos habría ocurrido tanto en tiempos de autorización para el comercio por el Pacífico como en la coyuntura de prohibición, medida que rigió formalmente desde 1604 hasta finales del siglo XVIII. De tal manera que, para esta segunda fase en donde el tránsito fue importante, la llegada de los asiáticos a la Ciudad de los Reyes requirió del guiño cómplice de las autoridades coloniales. En su carácter de virrey de Nueva España y posteriormente del Perú, el marqués de Montesclaros impulsó la movilidad espacial de los asiáticos. No resulta casual que el padrón ordenado por Montesclaros haya tenido un interés especial por empadronar a los asiáticos instalados en la ciudad de Lima.

Un punto que destacamos de las características de los chinos, japoneses y los de la India portuguesa es que no solo contrajeron matrimonio entre ellos sino que también se unieron con otros grupos étnicos como negros africanos e indígenas locales, alimentando un temprano proceso de mestizaje. Dentro del grupo de los asiáticos los procedentes de la India de Portugal presentaron mayores dificultades para su inserción en la Lima colonial. Fue el grupo en el cual primó la esclavitud y los que estuvieron prácticamente sujetos al trabajo servil doméstico. Por el contrario, los chinos o japoneses alcanzaron mejores condiciones materiales para su supervivencia; situación que se expresó en la constitución de familias mestizas. Estas familias habrían logrado una mayor integración al conjunto de la población al desarrollar oficios artesanales, en algunos casos de manera independiente.

La gran mayoría de los asiáticos que ingresaron a Lima, particularmente los de la India de Portugal, lo hicieron como esclavos; condición social que habrían adquirido desde temprano, es decir, desde su salida de Filipinas con el galeón de 
Manila. Si bien existieron esclavos chinos y japoneses, su número es muy inferior en comparación a los de la India de Portugal. Los chinos fueron mayormente libres y lograron desarrollar el oficio de soleteros y abridores de cuellos en la ciudad de Lima; una actividad laboral que quedó prácticamente concentrada en sus manos. La concentración de los chinos en una tarea u oficio específico fue un hecho que ocurrió tanto en Lima como en la ciudad de México, en este caso en la profesión de barberos. El hecho no se podría considerar únicamente como una fuerza de exclusión generada por la comunidad en su conjunto, ni tampoco por las relaciones de subordinación que se establecieron sobre los asiáticos. Podría definirse también como una práctica de conservación, como mecanismos de preservación social de un grupo socioétnico venido de tierras muy distantes.

\section{Referencias citadas}

\section{Fuentes primarias}

Archivo General de Indias, Sevilla (AGI)

Archivo General de la Nación, México

Biblioteca Nacional de España, Madrid

Biblioteca Nacional de Francia

\section{Fuentes secundarias}

BORAH, W., 1954 - Early Colonial Trade and Navigation between Mexico and Peru, 170 pp.; Berkeley: University of California Press.

CALVO, T., 1983 - Japoneses en Guadalajara: blancos de honor durante el seiscientos mexicano. Revista de Indias, XLIII, 172: 531-547.

CHARNEY, P., 1988 - El indio urbano. Un análisis económico y social de la población india de Lima en 1613. Histórica, XII, 1: 5-33.

COLíN, F., 1904 [1663] - Labor evangélica de los obreros de la Compañía de Jesús en las Islas Filipinas por el P. Francisco Colin de la misma compañía: Nueva edición ilustrada con copia de notas y documentos para la crítica de la historia general de la soberanía de España en Filipinas por el padre Pablo Pastells, S. J., 202 pp.; Barcelona: Henrich y Compañía.

COOK, D., 1968 - Padrón de los indios de Lima en 1613, 547 pp.; Lima: Universidad Nacional Mayor de San Marcos. Seminario de Historia Rural Andina.

COOK, D., 1976 - Les Indiens immigrés à Lima au début du XVII ${ }^{e}$ siècle. Cahiers des Amériques Latines, 13/14: 33-50.

FLORES, R., 2005 - El secreto encanto de Oriente. Comerciantes peruanos en la ruta transpacífica (1590-1610). In: Passeurs, mediadores culturales y agentes de la 
primera globalización en el mundo ibérico, siglos XVI-XIX, (S. O'Phelan Godoy \& C. Salazar Soler, eds.): 377-409; Lima: Instituto Francés de Estudios Andinos, Pontificia Universidad Católica del Perú.

ISRAEL, J., 1975 - Race, Class, and Politics in Colonial Mexico, 1610-1670, 305 pp.; Oxford: Oxford University Press.

IWASAKI CAUTI, F., 1992 - Extremo Oriente y Perú en el siglo XVI, 286 pp.; Madrid: MAPFRE.

JARAMILLO, M., 1992 - Migraciones y formación de mercados laborales: la fuerza de trabajo indígena de Lima a comienzos del siglo XVII. Revista Economía, XV (29-30): 265-320; Lima: Departamento de Economía, Pontificia Universidad Católica del Perú.

LATASA VASALLO, P., 2002 - Limitaciones legales al comercio transpacífico: actitud del virrey Montesclaros. In: Derecho y administración pública en las Indias Hispánicas (F. Barrios, ed.), vol. I: 877-897; Cuenca: Ediciones de la Universidad de Castilla-La Mancha.

LATASA VASALLO, P. \& FARIÑAS DE ALBA, M., 1991 - El comercio triangular entre Filipinas, México y Perú a comienzos del siglo XVII. Revista Naval, IX (35): 13-35.

LEÓN-PORTILLA, M., 1981 - La Embajada de los Japoneses en México, 1614. El testimonio en nahuatl del Cronista Chimalpahin. Estudios de Asia y África, 16, 2 (48): 215-241.

LOHMANN VILLENA, G., 1982 - Algunas notas documentales sobre la presencia de alemanes en el Perú virreinal. Anuario de Historia de América Latina: Jahrbuch für Geschichte Lateinamerikas, 19: 110-116.

LOHMANN VILLENA, G., 1983 - Los Regidores andaluces del Cabildo de Lima. In: II Jornadas Andalucía y América, vol. II: 223-272; Sevilla: Escuela de Estudios Hispanoamericanos.

MEDINA, J. T., 1956 - Historia del Tribunal del Santo Oficio de la Inquisición de Lima, 15691820, 197 pp.; Chile: Fondo Histórico y Biográfico J. T. Medina.

NAVARRO GARCÍA, L., 1965 - El comercio interamericano por la Mar del Sur en la Edad Moderna. Revista de Historia, 23: 11-55; Caracas.

OROPEZA, D., 2007 - Los «indios chinos» en la Nueva España: la inmigración de la Nao de China, 1565-1700, 480 pp.; México: Centro de Estudios Históricos, El Colegio de México. Tesis de doctorado.

OROPEZA, D., 2011 - La esclavitud asiática en el virreinato de la Nueva España, 15651673. Historia Mexicana, LXI, 1: 5-57.

PALMA, P., 2013 - Los indios del Xapón. Primeras migraciones japonesas al virreinato del Perú, siglos XVI-XVII. Seda. Revista de Estudios Asiáticos. Disponible en: https:// www.academia.edu/10317123/Primeras_migraciones_japonesas_al_virreinato_del_ Per\%C3\%BA_siglos_XVI-XVII

PAZ Y ESPESO, J., 1933 - Catálogo de Manuscritos de América existentes en la Biblioteca Nacional, 814 pp.; Madrid.

REYES, M. \& PALACIOS, H., 2011 - Japanese Merchants in 17th Century Guadalajara. Revista Iberoamericana, 22 (2): 191-237; Seúl: Institute of Latin American Studies Seoul National University.

RODRÍGUEZ VICENTE, M., 1968 - Los extranjeros y el mar en Perú (fines del siglo XVI y comienzos del XVII). In: Anuario de Estudios Hispanoamericanos, XXV: 619-629; Sevilla: Escuela de Estudios Hispanoamericanos.

ROSENBLAT, A., 1939 - El desarrollo de la población indígena en América. Anales de la Sociedad de Geografía e Historia, 3: 367-379.

SÁNCHEZ ALBORNOZ, N., 1977 - La población de América Latina desde los tiempos precolombinos hasta el año 2000, 312 pp.; Madrid: Alianza. 
SCHURZ, W. L., 1992 [1939] - El Galeón de Manila, 357 pp.; Madrid: Edición de Cultura Hispánica.

SCOTT, W. H., 1991 - Slavery in the Spanish Philippines, 78 pp.; Manila: De La Salle University Press.

SEIJAS, T., 2008 - The Portuguese slave trade to Spanish Manila: 1580-1640. Itinerario, XXXII (1): 19-38.

SLACK, E., 2010 - Sinifying New Spain: Cathay's Influence on Colonial Mexico via the Nao de China. In: The Chinese in Latin America and the Caribbean (W. Look \& T. Chee Beng, eds.): 7-34; Leiden-Boston: Brill.

SOLA, E., 1973 - Notas sobre el comercio hispano japonés en los siglos XVI y XVII. Hispania, 124: 265-283.

SUÁREZ, M., 1995 - Comercio y fraude en el Perú colonial. Las estrategias mercantiles de un banquero, 137 pp.; Lima: Instituto de Estudios Peruanos, Banco Central de Reserva del Perú.

VARGAS UGARTE, R., 1954 - Historia del Perú. Virreinato (siglo XVII), tomo 2, 501 pp.; Lima: Ediciones Librería Studium S. A.

WACHTEL, N., 2001 - La Foi Du Souvenir. Labyrinthes Marranes, 500 pp.; París: Éditions du Seuil. 
Asiáticos en Lima a principios del siglo XVII

\begin{tabular}{|c|c|c|c|c|c|c|}
\hline 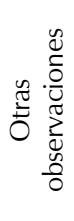 & 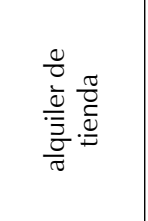 & 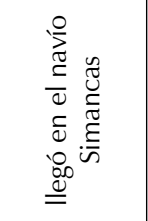 & 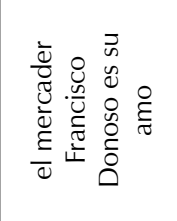 & 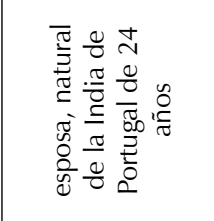 & 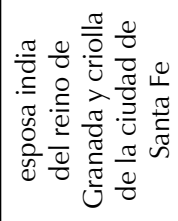 & \\
\hline 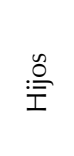 & & & & & 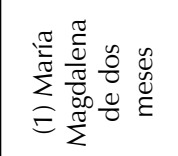 & \\
\hline 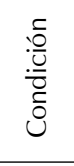 & & & $\begin{array}{l}\stackrel{0}{\pi} \\
\stackrel{\pi}{\breve{d}} \\
0\end{array}$ & & & \\
\hline $\begin{array}{l}\frac{.}{0} \\
\frac{0}{00} \\
\frac{0}{20} \\
\frac{0}{2}\end{array}$ & 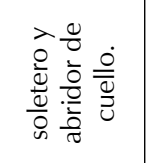 & 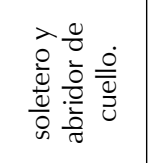 & 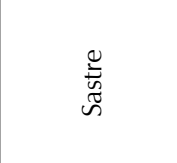 & 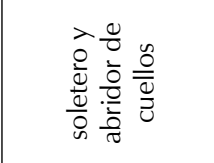 & 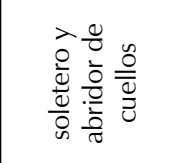 & 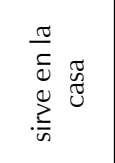 \\
\hline 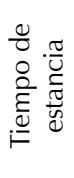 & $\begin{array}{l}\stackrel{\infty}{0} \\
\text { 离 } \\
m\end{array}$ & & & 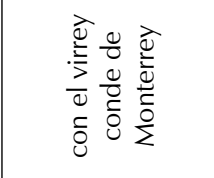 & 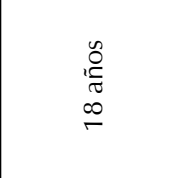 & $\begin{array}{l}\stackrel{n}{0} \\
\stackrel{0}{0} \\
\stackrel{0}{0}\end{array}$ \\
\hline 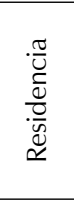 & 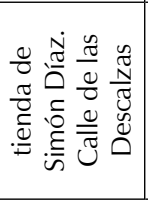 & 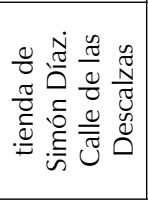 & 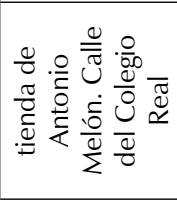 & 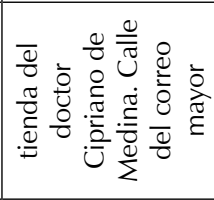 & 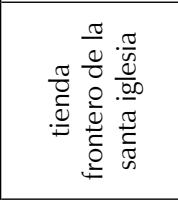 & 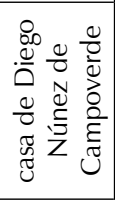 \\
\hline $\begin{array}{l}\text { 유 } \\
\text { 离 }\end{array}$ & 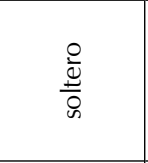 & $\frac{\stackrel{\circ}{\pi}}{\frac{\tilde{s}}{0}}$ & 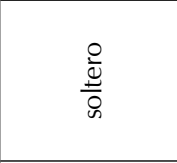 & 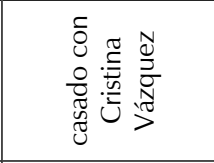 & 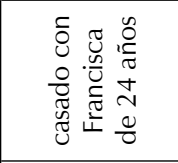 & $\frac{\pi}{\frac{\pi}{\pi}}$ \\
\hline 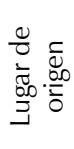 & 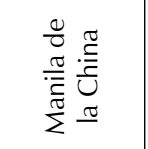 & 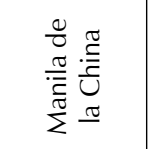 & 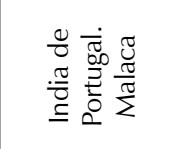 & 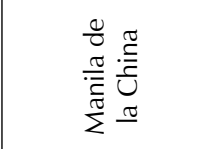 & 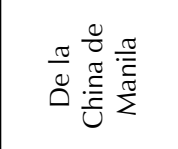 & 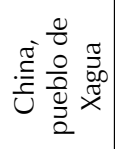 \\
\hline 胥 & 가 & q & $\dot{m}$ & q & $\stackrel{\llcorner}{m}$ & $\stackrel{\sim}{\sim}$ \\
\hline 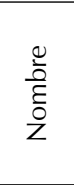 & 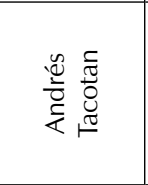 & $\begin{array}{l}\frac{\pi}{0} \\
\frac{0}{2} \\
\frac{0}{2} \\
\frac{0}{0} \\
\frac{0}{20}\end{array}$ & 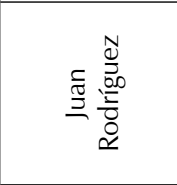 & 这 & 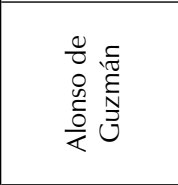 & 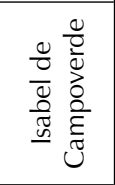 \\
\hline$\stackrel{\circ}{Z}$ & - & $\sim$ & $m$ & 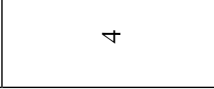 & in & 0 \\
\hline
\end{tabular}




\begin{tabular}{|c|c|c|c|c|c|c|c|c|}
\hline 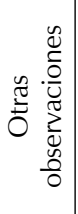 & 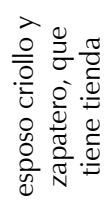 & & 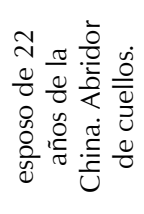 & 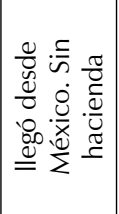 & 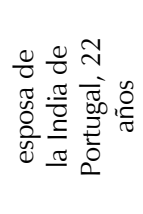 & 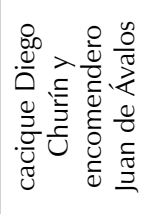 & 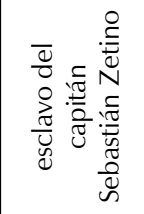 & 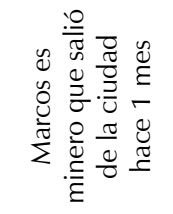 \\
\hline$\frac{\mathscr{n}}{\frac{\tilde{T}}{2}}$ & & & ' & & & & & \\
\hline 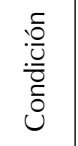 & & & ' & 1 & & & $\frac{\substack{\pi \\
\cup}}{\mathscr{d}}$ & $\frac{\pi}{\stackrel{\pi}{U}}$ \\
\hline 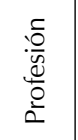 & $=$ & $=$ & 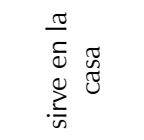 & 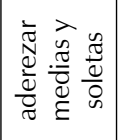 & $\begin{array}{l}\frac{0}{0} \\
\frac{0}{0} \\
\frac{0}{\frac{0}{0}} \\
\frac{0}{0} \\
\frac{0}{0}\end{array}$ & 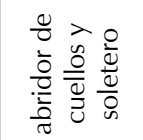 & & \\
\hline 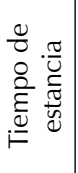 & 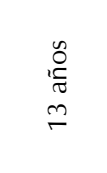 & 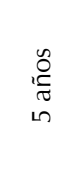 & 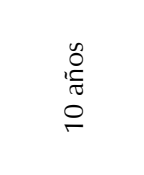 & 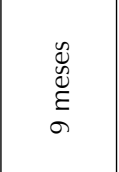 & 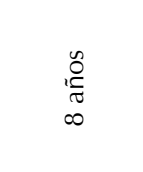 & 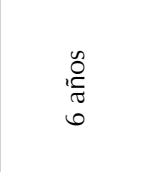 & 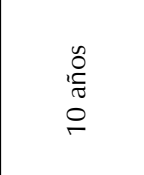 & 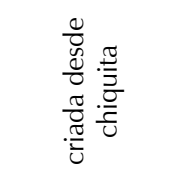 \\
\hline 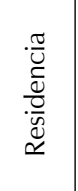 & $=$ & $=$ & 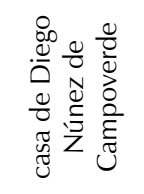 & 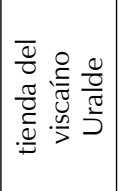 & 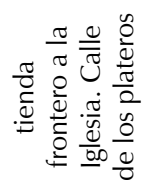 & 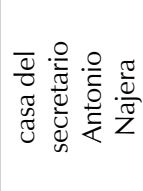 & 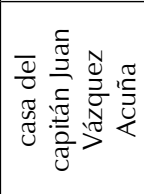 & 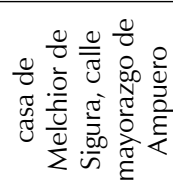 \\
\hline $\begin{array}{l}\frac{0}{0} \\
\text { 苟 }\end{array}$ & 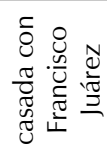 & $\frac{\frac{\pi}{4}}{\frac{ \pm}{0}}$ & 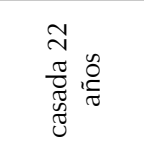 & 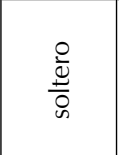 & 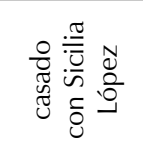 & 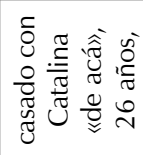 & 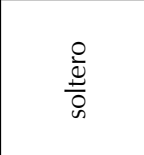 & 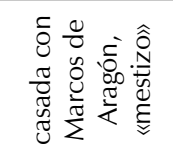 \\
\hline 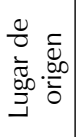 & 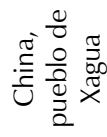 & 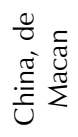 & 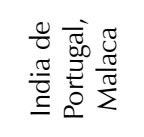 & 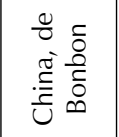 & 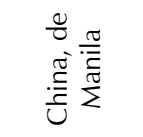 & 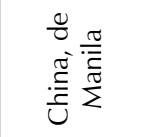 & 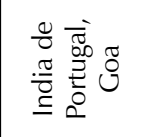 & 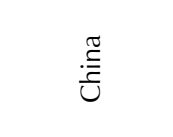 \\
\hline 疍 & ஓ & $\stackrel{0}{m}$ & $\stackrel{\sim}{\sim}$ & $\ddot{m}$ & $\stackrel{\llcorner}{\sim}$ & ஓ & ี & \\
\hline $\begin{array}{l}\text { ֻँ } \\
\text { है } \\
\text { है }\end{array}$ & 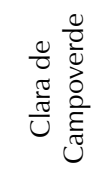 & 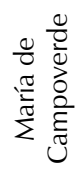 & 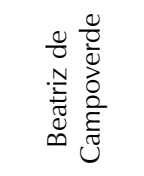 & 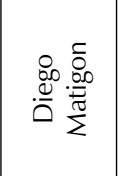 & 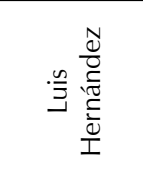 & 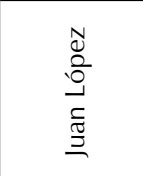 & 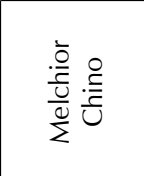 & 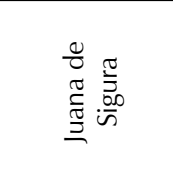 \\
\hline$\stackrel{\circ}{Z}$ & $\wedge$ & $\infty$ & $a$ & $\stackrel{ }{\circ}$ & $\mp$ & $\stackrel{\sim}{\sim}$ & $\stackrel{m}{\sim}$ & $\underset{\nabla}{ \pm}$ \\
\hline
\end{tabular}




\begin{tabular}{|c|c|c|c|c|c|c|c|c|}
\hline 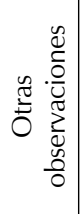 & & 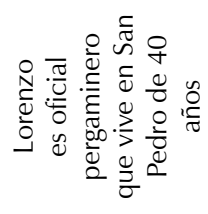 & 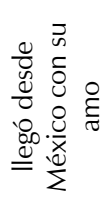 & 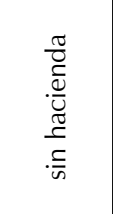 & & 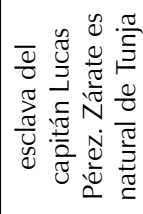 & 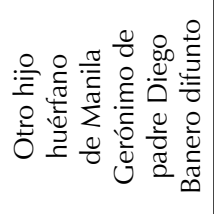 & \\
\hline 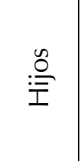 & & 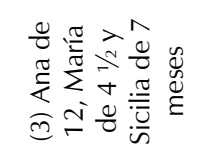 & & & & & 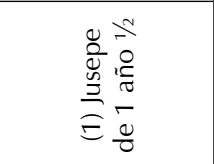 & \\
\hline $\begin{array}{l}: \frac{0}{U} \\
\frac{0}{0} \\
\check{0} \\
0\end{array}$ & 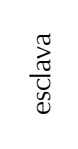 & $\stackrel{\circlearrowright}{\stackrel{\Xi}{\Xi}}$ & 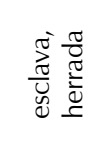 & & & $\frac{\pi}{\frac{\pi}{U}}$ & & 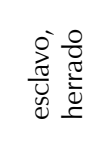 \\
\hline$\frac{\square}{\frac{0}{20}}$ & & & & 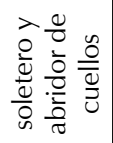 & 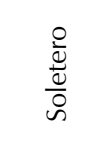 & & & \\
\hline 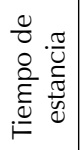 & $\begin{array}{l}\stackrel{n}{0} \\
\stackrel{0}{\pi} \\
m \\
n\end{array}$ & 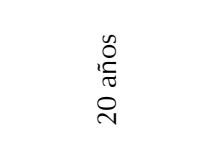 & $\begin{array}{l}\stackrel{0}{\stackrel{\overbrace{}}{\pi}} \\
- \\
-\end{array}$ & 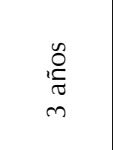 & $\begin{array}{l}\stackrel{\circ}{\stackrel{ர}{ர}} \\
-\end{array}$ & & 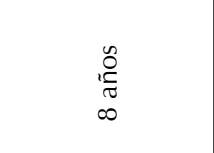 & $\begin{array}{l}\stackrel{n}{0} \\
10 \\
0 \\
0 \\
0 \\
\text { Ln }\end{array}$ \\
\hline 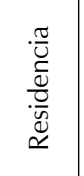 & 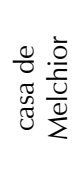 & $=$ & 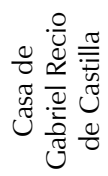 & 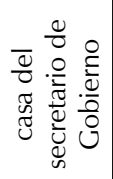 & 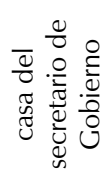 & 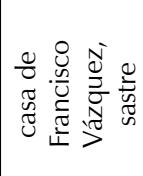 & 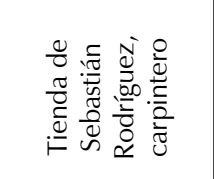 & 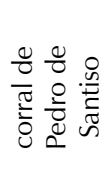 \\
\hline 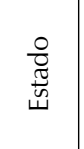 & 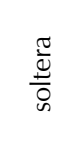 & 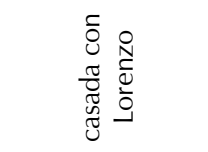 & $\frac{\frac{\pi}{4}}{\frac{\pi}{0}}$ & 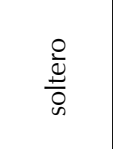 & 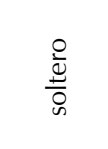 & 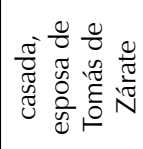 & 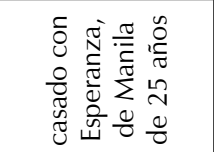 & 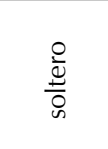 \\
\hline 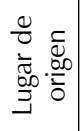 & 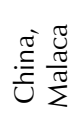 & 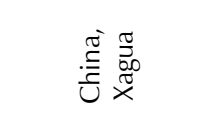 & 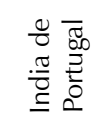 & $\begin{array}{l}\frac{\sigma}{0} \\
\frac{0}{\sigma}\end{array}$ & $\begin{array}{l}\frac{\sigma}{0} \\
\frac{0}{\sigma]}\end{array}$ & $\underset{\stackrel{\Xi}{\Xi}}{\stackrel{\Xi}{U}}$ & 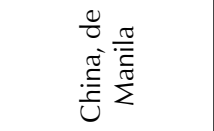 & 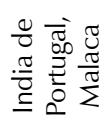 \\
\hline 胥 & $\stackrel{m}{m}$ & ㅇ & 우 & $\stackrel{\sim}{\sim}$ & $\stackrel{\infty}{\leftarrow}$ & & $\stackrel{\text { m }}{ }$ & $\stackrel{\bullet}{\sim}$ \\
\hline $\begin{array}{l}\text { ڤั) } \\
\text { है } \\
\text { Zे }\end{array}$ & $\begin{array}{l}\frac{0}{0} \\
\frac{\pi}{\frac{\pi}{5}} \\
\frac{0}{0} \\
\frac{0}{0}\end{array}$ & 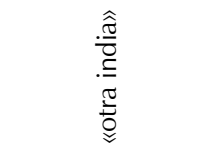 & $\frac{\widetilde{\sigma}}{\frac{\mathbb{U}}{W}}$ & 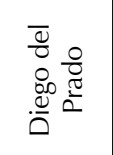 & 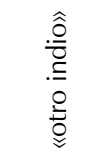 & 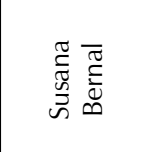 & 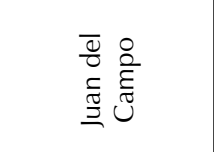 & 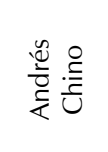 \\
\hline$\stackrel{\circ}{Z}$ & $\stackrel{\operatorname{Ln}}{\sim}$ & $\stackrel{\bullet}{\leftarrow}$ & 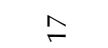 & $\stackrel{\infty}{\sim}$ & $\stackrel{\sigma}{\square}$ & $\stackrel{\sim}{\text { 尺 }}$ & $\bar{v}$ & $\approx$ \\
\hline
\end{tabular}




\begin{tabular}{|c|c|c|c|c|c|c|}
\hline 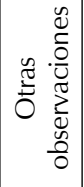 & & & 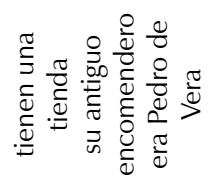 & 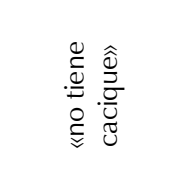 & 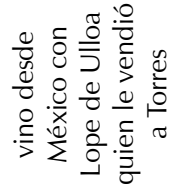 & \\
\hline 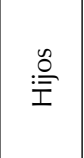 & 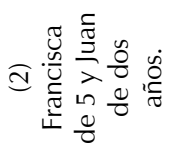 & & 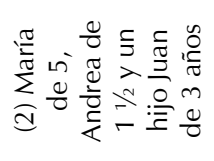 & 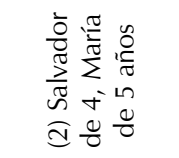 & & 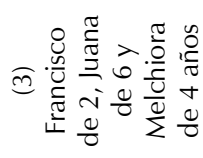 \\
\hline 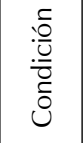 & & $\frac{\widetilde{\pi}}{\frac{\pi}{u}}$ & & 㫕 & $\frac{\stackrel{0}{\pi}}{\underline{U}}$ & 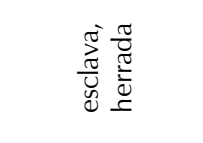 \\
\hline $\begin{array}{l}\frac{0}{0} \\
\frac{0}{0} \\
\frac{0}{0} \\
2\end{array}$ & 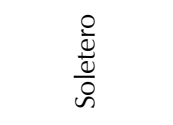 & & $\frac{\frac{O}{\mathbb{U}}}{\frac{0}{0}}$ & $\frac{\frac{O}{4}}{\frac{\pi}{0}}$ & & \\
\hline 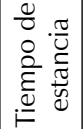 & 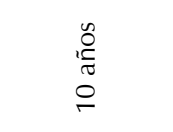 & 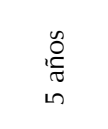 & $\begin{array}{l}\stackrel{0}{0} \\
\stackrel{\tilde{J}}{\pi} \\
\stackrel{ \pm}{\tau}\end{array}$ & $\begin{array}{l}\stackrel{2}{0} \\
\text { c } \\
0 \\
\circ\end{array}$ & & 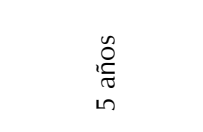 \\
\hline 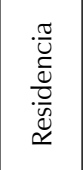 & 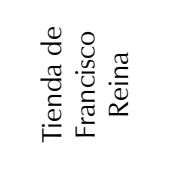 & 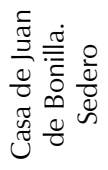 & 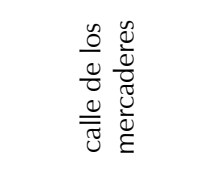 & 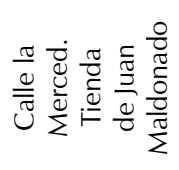 & 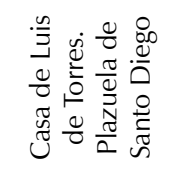 & 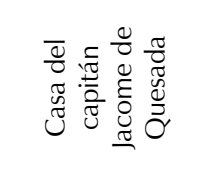 \\
\hline $\begin{array}{l}\frac{0}{0} \\
\frac{\pi}{\omega}\end{array}$ & 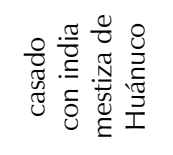 & 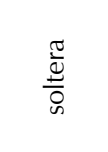 & 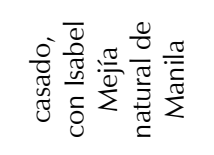 & 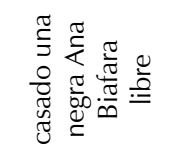 & 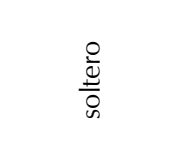 & 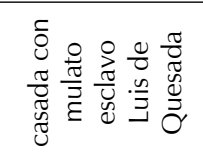 \\
\hline 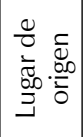 & 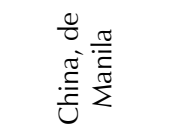 & 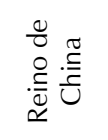 & 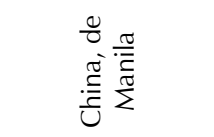 & 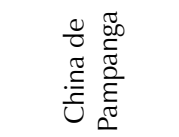 & 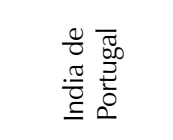 & 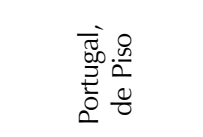 \\
\hline 嶒 & 우 & 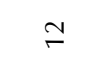 & $\tilde{m}$ & 우 & $\stackrel{\infty}{\sim}$ & $\stackrel{\infty}{\sim}$ \\
\hline $\begin{array}{l}\text { Uूँ } \\
\text { है } \\
\text { Zे }\end{array}$ & 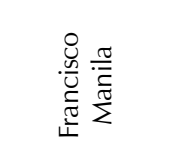 & 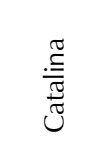 & 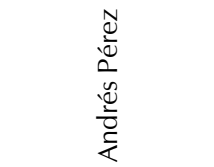 & $\stackrel{\text { 음 }}{\underline{\underline{9}}}$ & $\begin{array}{l}\frac{0}{\bar{g}} \\
\underline{\underline{\underline{I}}}\end{array}$ & 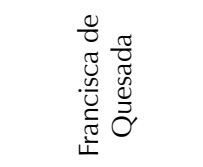 \\
\hline$\stackrel{\circ}{Z}$ & $\stackrel{\sim}{\sim}$ & $\stackrel{+}{\sim}$ & $\stackrel{\llcorner}{\sim}$ & $\stackrel{\bullet}{v}$ & $\hat{\sim}$ & $\stackrel{\infty}{\sim}$ \\
\hline
\end{tabular}




\begin{tabular}{|c|c|c|c|c|c|c|c|}
\hline 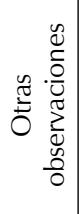 & & & 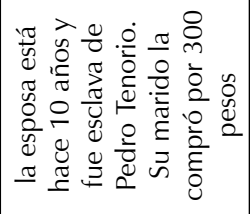 & & 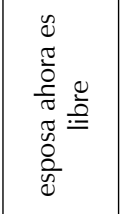 & 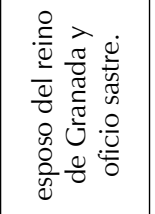 & \\
\hline 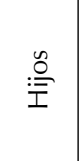 & & 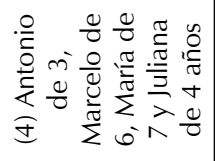 & 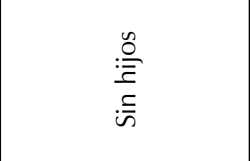 & & 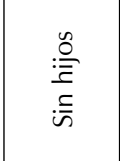 & & 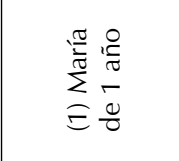 \\
\hline $\begin{array}{l}: \frac{0}{0} \\
\frac{.0}{0} \\
\tilde{0}\end{array}$ & & 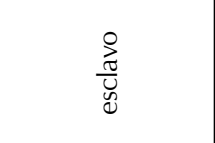 & & 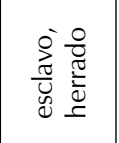 & & 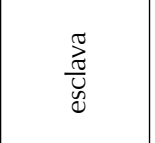 & $\frac{\widetilde{\pi}}{\tilde{U}}$ \\
\hline 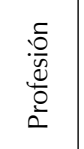 & 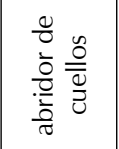 & & 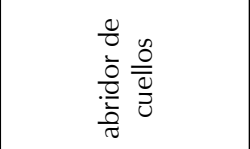 & & $\begin{array}{l}\frac{0}{0} \\
\frac{0}{0} \\
\frac{0}{0} \frac{0}{0} \\
\frac{0}{0}\end{array}$ & & \\
\hline 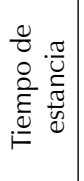 & & 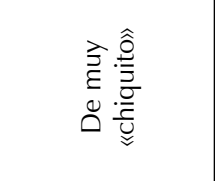 & 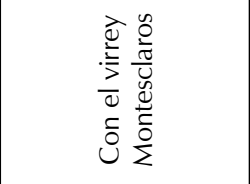 & $\begin{array}{l}\stackrel{n}{0} \\
\stackrel{0}{\pi} \\
\text { ద }\end{array}$ & 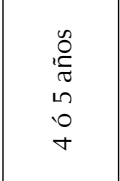 & 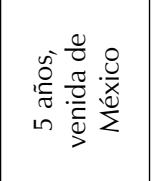 & \\
\hline 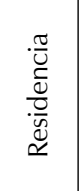 & 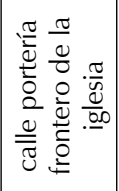 & 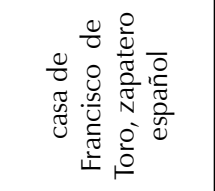 & 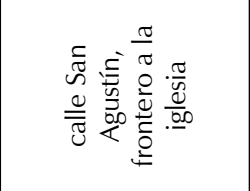 & 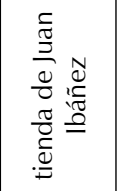 & 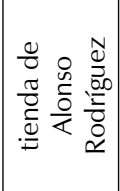 & 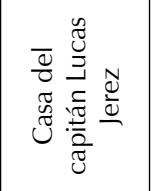 & 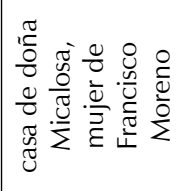 \\
\hline $\begin{array}{l}\frac{0}{0} \\
\text { 䓌 }\end{array}$ & $\frac{O}{\frac{O}{\Psi}}$ & 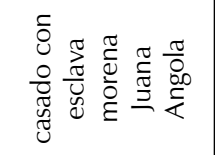 & 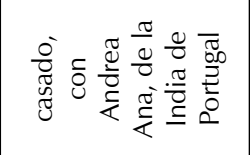 & $\frac{O}{\stackrel{O}{\Psi}}$ & 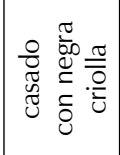 & 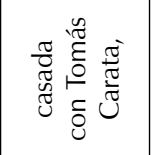 & $\frac{\pi}{\frac{\pi}{\pi}}$ \\
\hline 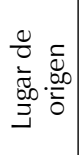 & 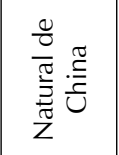 & 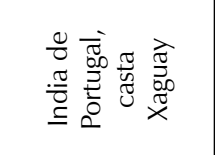 & 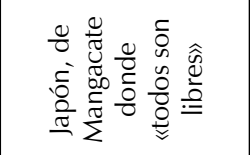 & 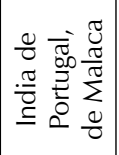 & 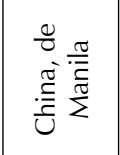 & 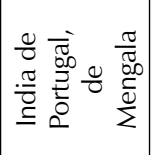 & 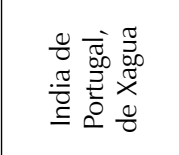 \\
\hline $\begin{array}{l}\bar{\pi} \\
\text { d } \\
\end{array}$ & $\approx$ & $\stackrel{ \pm}{\sim}$ & $\stackrel{\sim}{\sim}$ & $\stackrel{\infty}{\leftarrow}$ & $\stackrel{\sim}{\sim}$ & ஓ & $\stackrel{\infty}{-}$ \\
\hline 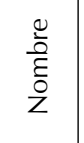 & 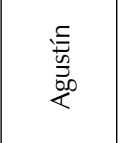 & $\begin{array}{l}\frac{0}{0} \\
\frac{U}{U}\end{array}$ & $\begin{array}{l}\stackrel{\circ}{\underline{\underline{S}}} \\
\underline{\underline{5}}\end{array}$ & 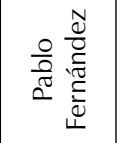 & 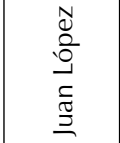 & 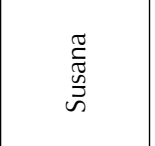 & $\frac{\pi}{\frac{\pi}{\pi}}$ \\
\hline$\stackrel{\circ}{Z}$ & $\stackrel{\curvearrowright}{\sim}$ & i & $\bar{m}$ & ๗ె & $\stackrel{m}{m}$ & $\stackrel{+}{m}$ & $\stackrel{\llcorner}{m}$ \\
\hline
\end{tabular}




\begin{tabular}{|c|c|c|c|c|c|c|c|}
\hline 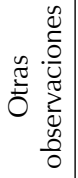 & & & & 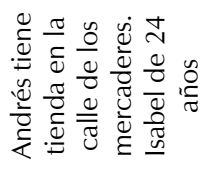 & 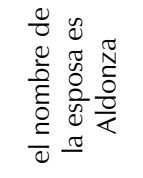 & 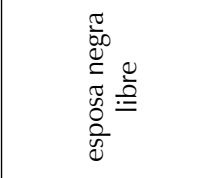 & \\
\hline 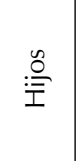 & & & & 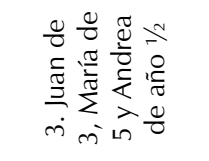 & & & \\
\hline 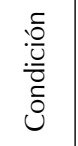 & 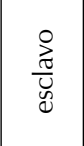 & 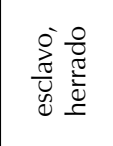 & & & 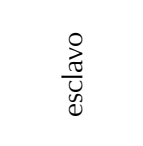 & & \\
\hline 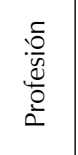 & & & 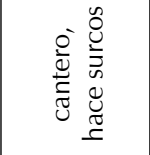 & $\frac{0}{\frac{0}{0}}$ & & 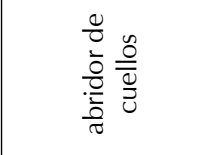 & \\
\hline 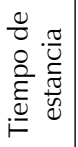 & & 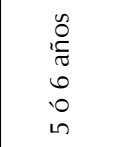 & 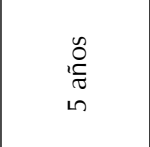 & & 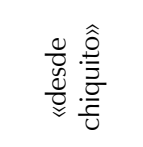 & 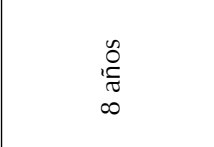 & \\
\hline 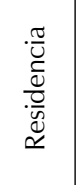 & 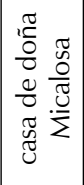 & 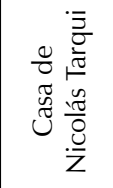 & 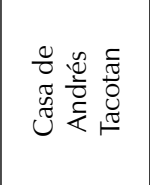 & 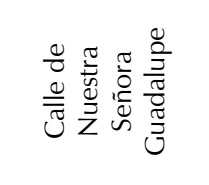 & 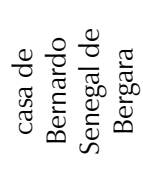 & 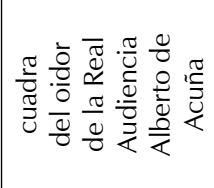 & 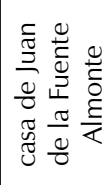 \\
\hline 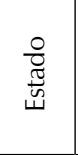 & 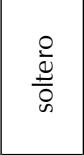 & 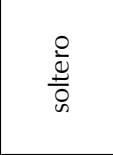 & 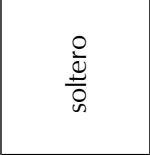 & 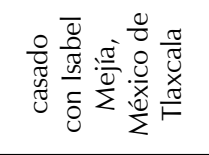 & 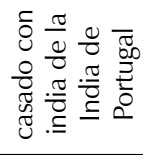 & 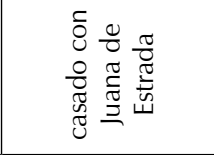 & \\
\hline 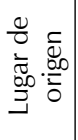 & 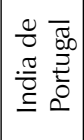 & 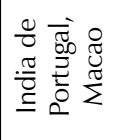 & 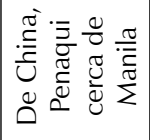 & 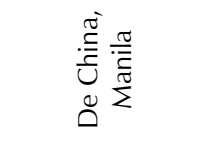 & 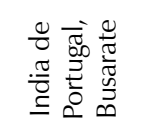 & 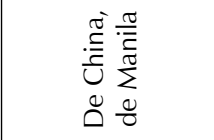 & 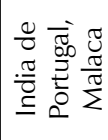 \\
\hline $\begin{array}{l}\bar{\sigma} \\
\text { J } \\
\end{array}$ & $\stackrel{\sim}{\sim}$ & $\stackrel{\stackrel{n}{\sim}}{ }$ & ஓे & & $\stackrel{\nabla}{\sim}$ & $\stackrel{\infty}{\sim}$ & ㄱ \\
\hline $\begin{array}{l}\frac{0}{0} \\
\frac{0}{0} \\
\text { Ż }\end{array}$ & 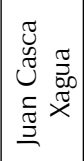 & 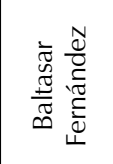 & $\begin{array}{l}\stackrel{ }{\frac{0}{\underline{I}}} \\
\end{array}$ & 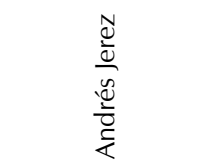 & $\begin{array}{l}\frac{0}{0} \\
\frac{\pi}{\pi} \\
\frac{\pi}{0} \\
\text { 总 } \\
0\end{array}$ & 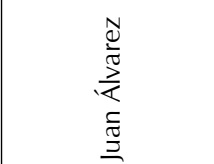 & 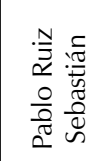 \\
\hline$\stackrel{\circ}{Z}$ & r & $\hat{m}$ & $\infty$ & mे & 우 & ఫ & ช้ \\
\hline
\end{tabular}




\begin{tabular}{|c|c|c|c|c|c|c|c|c|}
\hline 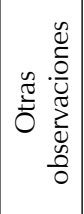 & 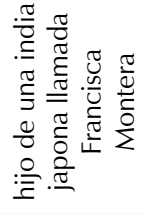 & 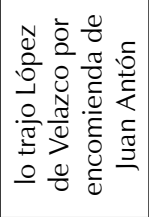 & 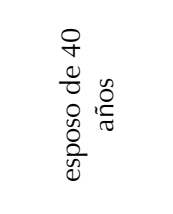 & 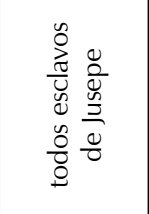 & & & & \\
\hline 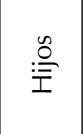 & & & & 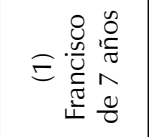 & & & & \\
\hline $\begin{array}{l}: \frac{0}{0} \\
: \frac{0}{0} \\
0 \\
0\end{array}$ & 苛 & $\frac{\rho^{\prime}}{\frac{\pi}{0}}$ & & 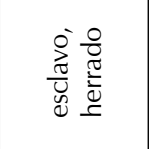 & 突遂 & 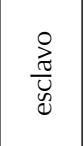 & 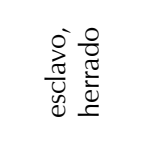 & 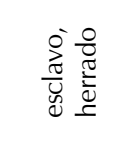 \\
\hline$\frac{c}{\frac{0}{n}}$ & 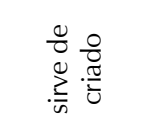 & $\begin{array}{l}\overline{i \bar{c}} \\
\stackrel{\mathbb{0}}{\bar{k}}\end{array}$ & 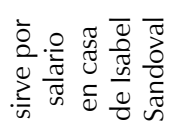 & & & & 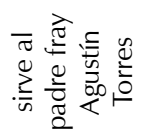 & \\
\hline 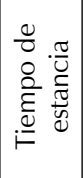 & 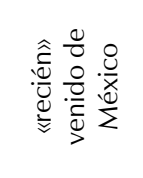 & 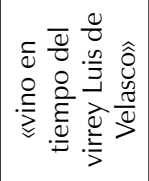 & $\begin{array}{l}\stackrel{n}{2} \\
\text { ?0 } \\
\infty \\
\infty\end{array}$ & & & & & \\
\hline 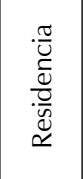 & 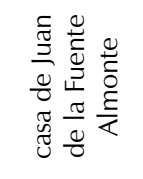 & 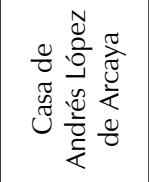 & 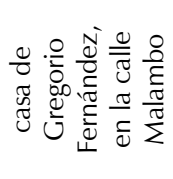 & 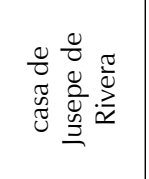 & 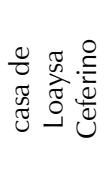 & 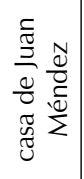 & 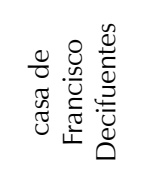 & 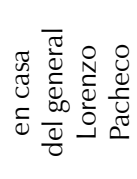 \\
\hline $\begin{array}{l}\frac{0}{0} \\
\text { i⿱艹 } \\
\text { 山⿸厂 }\end{array}$ & 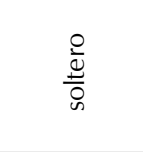 & 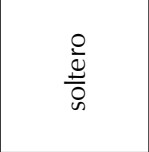 & 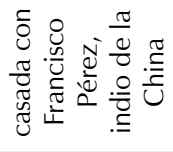 & 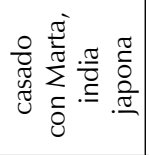 & 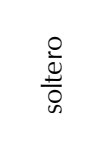 & 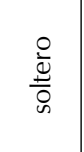 & 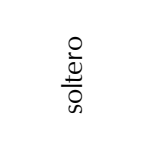 & 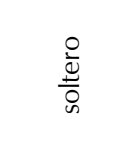 \\
\hline 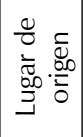 & 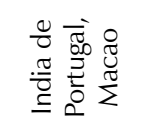 & 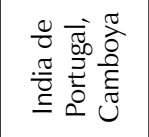 & 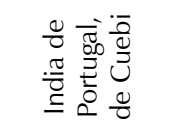 & 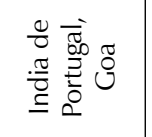 & 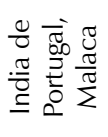 & 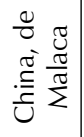 & 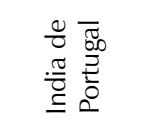 & 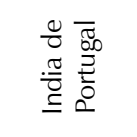 \\
\hline 尊 & $\stackrel{\infty}{\rightleftharpoons}$ & $\stackrel{\stackrel{n}{N}}{ }$ & $\stackrel{\infty}{\sim}$ & $\stackrel{\infty}{\sim}$ & ○े & $\stackrel{\sim}{\text { V }}$ & & $\stackrel{\llcorner}{\sim}$ \\
\hline $\begin{array}{l}\frac{0}{\circ} \\
\text { है } \\
\text { Z }\end{array}$ & 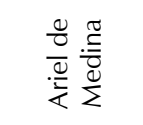 & $\approx$ & 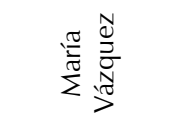 & 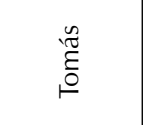 & 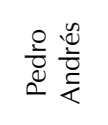 & $\frac{0}{\sqrt{0}}$ & $\frac{\mathscr{0}}{\frac{\mathscr{Q}}{0}}$ & 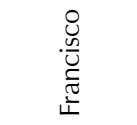 \\
\hline$\stackrel{\circ}{Z}$ & $\mathscr{F}$ & ஓ & $\stackrel{\llcorner}{+}$ & $\stackrel{+}{+}$ & f & $\stackrel{\infty}{+}$ & $\mathscr{q}$ & ㅇำ \\
\hline
\end{tabular}




\begin{tabular}{|c|c|c|c|c|c|c|c|c|c|}
\hline 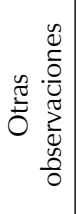 & & & & & & & & 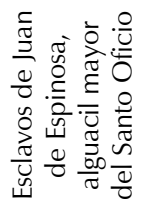 & \\
\hline 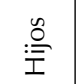 & & & & & & & & & \\
\hline 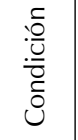 & 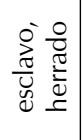 & 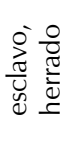 & & & & 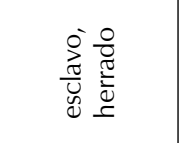 & 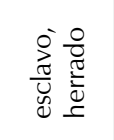 & 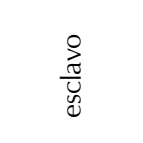 & \\
\hline 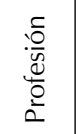 & & & & & & & & & \\
\hline 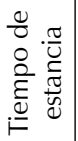 & & & & & & & & 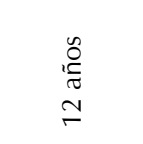 & \\
\hline 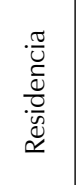 & $=$ & $=$ & 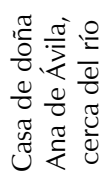 & 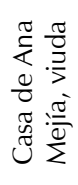 & $=$ & 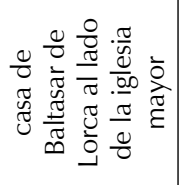 & 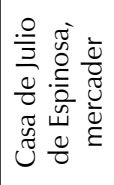 & 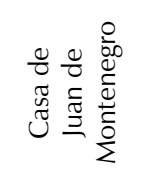 & 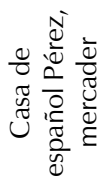 \\
\hline 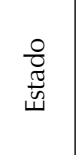 & 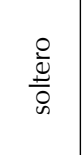 & 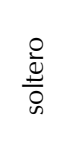 & 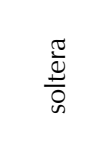 & 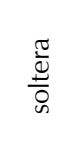 & 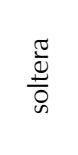 & 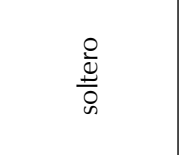 & & 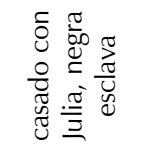 & $\frac{O}{\frac{O}{\Psi}}$ \\
\hline 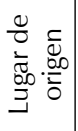 & 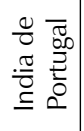 & 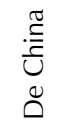 & 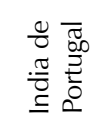 & 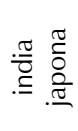 & 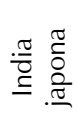 & 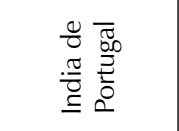 & 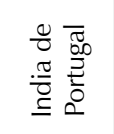 & 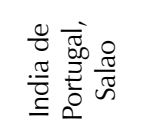 & 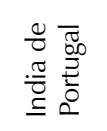 \\
\hline 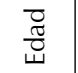 & $\stackrel{\sigma}{\sim}$ & ㄱ & 우 & & & $\stackrel{\text { }}{ }$ & $\stackrel{\sim}{\sim}$ & & ஓ \\
\hline $\begin{array}{l}\frac{\mathscr{\nu}}{0} \\
\text { है } \\
\text { Zे }\end{array}$ & 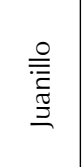 & 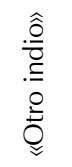 & $\begin{array}{l}\frac{\pi}{\tilde{U}} \\
\frac{\pi}{\pi} \\
\frac{\pi}{20} \\
\sum\end{array}$ & $\begin{array}{l}\bar{\Phi} \\
\stackrel{0}{0} \\
\stackrel{0}{0}\end{array}$ & $\begin{array}{l}\frac{\pi}{0} \\
\frac{0}{\pi} \\
\frac{\pi}{00} \\
\sum\end{array}$ & 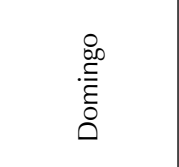 & 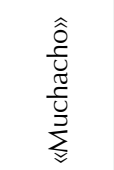 & $\stackrel{\stackrel{\circ}{g}}{\underline{\underline{g}}}$ & $\frac{0}{\frac{0}{0}}$ \\
\hline$\stackrel{\circ}{Z}$ & ᄃn & กิ & กิ & in & $\stackrel{L}{\stackrel{2}{L}}$ & L & ถิ & $\stackrel{\infty}{\infty}$ & in \\
\hline
\end{tabular}


Asiáticos en Lima a principios del siglo XVII

\begin{tabular}{|c|c|c|c|c|c|c|c|c|}
\hline 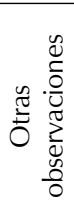 & & 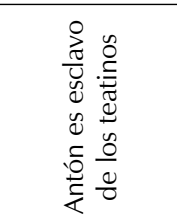 & & & & & & \\
\hline 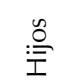 & & & & & & & & \\
\hline 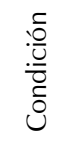 & 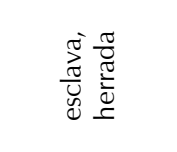 & & & & 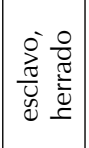 & & & \\
\hline 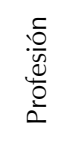 & & 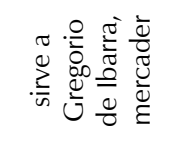 & $=$ & & & $\begin{array}{l}\frac{\overline{0}}{0} \\
\frac{\pi}{0} \\
\frac{0}{0} \\
\infty\end{array}$ & & 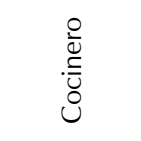 \\
\hline 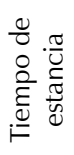 & & & & & & & & \\
\hline 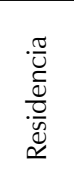 & 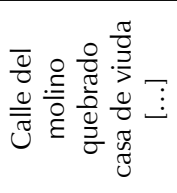 & 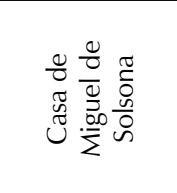 & $=$ & 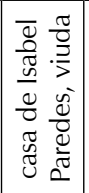 & 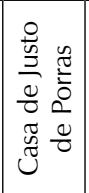 & 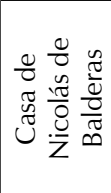 & 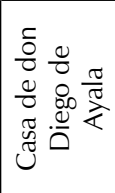 & 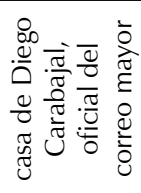 \\
\hline $\begin{array}{l}\text { 윰 } \\
\text { 㟧 }\end{array}$ & $\frac{\frac{\pi}{\tilde{J}}}{\frac{\pi}{0}}$ & 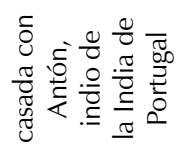 & & 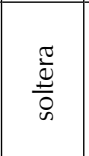 & 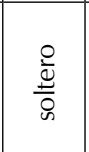 & $\frac{\stackrel{\circ}{\pi}}{\frac{0}{0}}$ & $\begin{array}{l}\frac{\pi}{\pi} \\
\frac{\pi}{0} \\
0\end{array}$ & \\
\hline 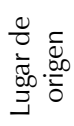 & 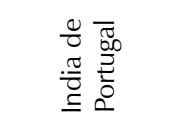 & 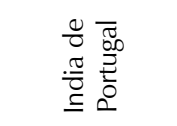 & 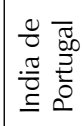 & 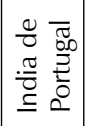 & 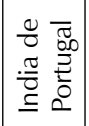 & 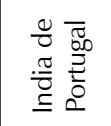 & 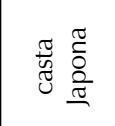 & 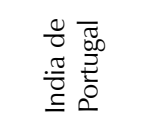 \\
\hline 疍 & & & & & & & & \\
\hline $\begin{array}{l}\text { ڤँ } \\
\text { है } \\
\text { Zे }\end{array}$ & $\begin{array}{l}\overline{\mathcal{Q}} \\
\stackrel{\widetilde{\widetilde{N}}}{\mathscr{\mathscr { N }}}\end{array}$ & $\frac{\widetilde{\pi}}{\underline{\underline{\Xi}}}$ & $\begin{array}{l}\frac{\pi}{\tilde{\pi}} \\
\frac{0}{\pi} \\
\frac{\pi}{0} \\
\sum\end{array}$ & 㺃 & $\begin{array}{l}\stackrel{0}{N} \\
\stackrel{0}{0} \\
\stackrel{0}{9}\end{array}$ & 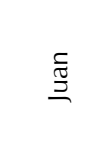 & 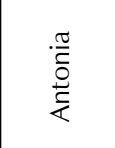 & 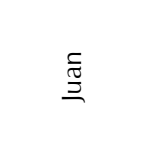 \\
\hline$\stackrel{\circ}{z}$ & 8 & $\overline{0}$ & $\widehat{~}$ & 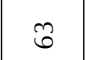 & ț & น & $\stackrel{8}{\circ}$ & $\hat{\sigma}$ \\
\hline
\end{tabular}




\begin{tabular}{|c|c|c|c|c|c|c|}
\hline 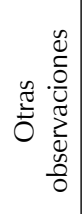 & & & & & & 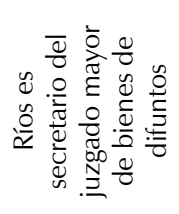 \\
\hline$\stackrel{\stackrel{0}{\overparen{I}}}{:}$ & & & & & & 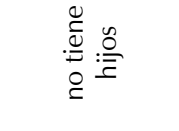 \\
\hline 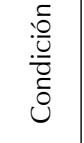 & 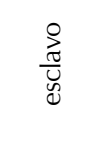 & 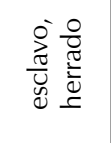 & 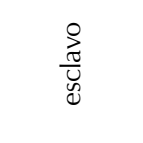 & & & $\frac{\widetilde{D}}{\frac{\pi}{U}}$ \\
\hline 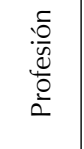 & & & & & & \\
\hline 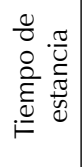 & & 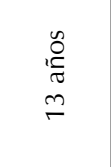 & & & & 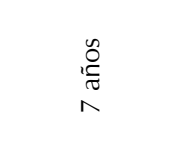 \\
\hline $\begin{array}{l}\cdot \frac{\pi}{U} \\
\frac{\mathscr{E}}{0} \\
\frac{0}{0} \\
\simeq \\
\simeq\end{array}$ & 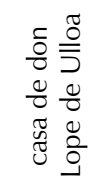 & 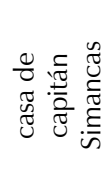 & 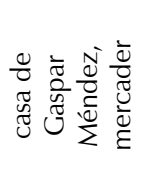 & 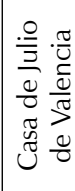 & 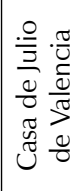 & 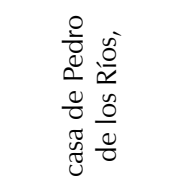 \\
\hline $\begin{array}{l}\frac{0}{0} \\
\text { ㅍّㅆ }\end{array}$ & 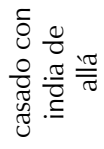 & 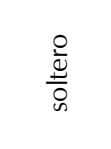 & 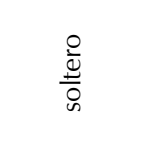 & 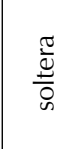 & $\frac{\frac{\pi}{\pi}}{\frac{\pi}{0}}$ & $\frac{\frac{\pi}{\pi}}{\frac{\pi}{0}}$ \\
\hline 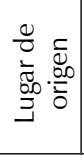 & 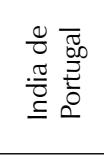 & 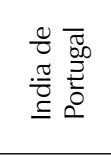 & 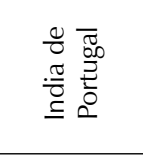 & 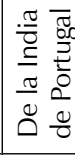 & 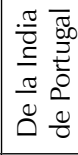 & 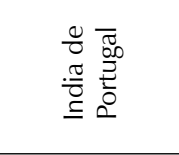 \\
\hline 胥 & & $\stackrel{\sigma}{\longrightarrow}$ & & & & 우 \\
\hline 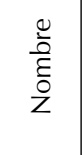 & $\begin{array}{l}\frac{ㅇ}{0} \\
\subseteq\end{array}$ & 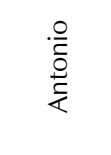 & $\frac{\frac{0}{\partial}}{\frac{\pi}{2}}$ & $\begin{array}{l}\frac{\pi}{\pi} \\
\stackrel{5}{\subseteq}\end{array}$ & $\begin{array}{l}\stackrel{\frac{\pi}{6}}{\underline{ }} \\
\end{array}$ & 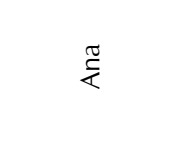 \\
\hline$\stackrel{\circ}{Z}$ & $\ddot{\sigma}$ & ఠิ & $\stackrel{P}{\wedge}$ & $\bar{\wedge}$ & $N$ & $\stackrel{M}{\wedge}$ \\
\hline
\end{tabular}

